\title{
Estimating Evapotranspiration with Land Data Assimilation Systems
}

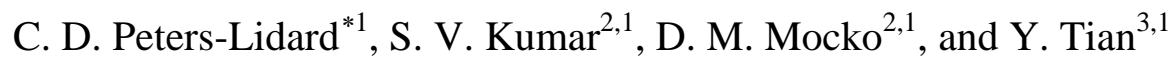

${ }^{1 *}$ NASA, Goddard Space Flight Center, Hydrological Sciences Branch, Code 614.3, Greenbelt, $M D$

${ }^{2}$ Science Applications International Corporation, Beltsville, $M D$

${ }^{3}$ Earth System Science Interdisciplinary Center, College Park, MD.

Submitted to SPECIAL ANNUAL REVIEW ISSUE OF HYDROLOGICAL PROCESSES July 2011, Revised October 2011

* Corresponding Author: Dr. Christa D. Peters-Lidard, NASA/Goddard Space Flight Center, Hydrological Sciences Branch, Code 614.3, Greenbelt, MD 20771 Phone: 301-614-5811; Fax: 301614-5808; E-mail: christa.peters@nasa.gov; URL: http://lis.gsfc.nasa.gov. 


\begin{abstract}
Advancements in both land surface models (LSM) and land surface data assimilation, especially over the last decade, have substantially advanced the ability of land data assimilation systems (LDAS) to estimate evapotranspiration (ET). This article provides a historical perspective on international LSM intercomparison efforts and the development of LDAS systems, both of which have improved LSM ET skill. In addition, an assessment of ET estimates for current LDAS systems is provided along with current research that demonstrates improvement in LSM ET estimates due to assimilating satellite-based soil moisture products. Using the Ensemble Kalman Filter in the Land Information System, we assimilate both NASA and Land Parameter Retrieval Model (LPRM) soil moisture products into the Noah LSM Version 3.2 with the North American LDAS phase 2 (NLDAS-2) forcing to mimic the NLDAS-2 configuration. Through comparisons with two global reference ET products, one based on interpolated flux tower data and one from a new satellite ET algorithm, over the NLDAS2 domain, we demonstrate improvement in ET estimates only when assimilating the LPRM soil moisture product.
\end{abstract}

\title{
Keywords
}

Land surface modeling, land data assimilation systems, evapotranspiration, soil moisture assimilation 


\section{INTRODUCTION}

2 Land surface models predict terrestrial water, energy, momentum, and in some cases,

3 biogeochemical exchange processes by solving the governing equations of the soil-vegetation-

4 snowpack medium based on atmospheric boundary conditions including precipitation, radiation,

5 wind, temperature, humidity and pressure. By constraining land surface models with observed

6 atmospheric boundary conditions and land surface states, land surface data assimilation improves

7 our ability to understand and predict terrestrial water and energy fluxes and states, including

8 evapotranspiration. The ability to predict evapotranspiration is critical for applications in weather

9 and climate prediction, agricultural forecasting, water resources management, and hazard

10 mitigation (e.g., NRC, 2010; 2011). Until recently, global or continental land surface modeling at

11 horizontal scales of $1 \mathrm{~km}$ or finer was infeasible due to limits in computational and observational

12 resources.

13

14 Land Data Assimilation Systems (LDAS, Figure 1), are typically run “uncoupled” (or 15 "offline”) to estimate water and energy fluxes and states using observationally-based 16 precipitation, radiation and meteorological inputs. However, they may also be run "coupled” to 17 an atmospheric model for weather forecasts.

This paper reviews current and developing capabilities for estimating evapotranspiration

20 (ET) using land surface models (LSMs) as part of an LDAS. First, we present a survey of land

21 surface modeling for ET estimation, including recent intercomparison studies and LDAS efforts.

22 Next, we compare LSM ET estimates from current LDAS systems to global gridded tower-based 23 and remote sensing-based flux estimates. Finally, we present the results from simulations that 
24 employ data assimilation (DA) of remotely sensed soil moisture measurements to improve LSM

25 ET estimates.

27 BACKGROUND

28 The ability of LSMs or soil-vegetation-atmosphere transfer schemes (SVATS) to predict 29 evapotranspiration has advanced significantly since the original bucket (Manabe, 1969), Simple 30 Biosphere (SiB; Sellers et al., 1986) and Biosphere-Atmosphere Transfer Scheme (BATS; 31 Dickinson et al., 1986) models pioneered at the National Oceanic and Atmospheric

32 Administration's Geophysical Fluid Dynamics Laboratory (NOAA/GFDL), National

33 Aeronautics and Space Administration's Goddard Space Flight Center (NASA/GSFC) and the

34 National Center for Atmospheric Research (NCAR), respectively. Numerous advancements in 35 second-generation LSMs have brought additional focus to snow physics and hydrology, such as 36 the community Noah (Ek et al., 2003; Barlage et al., 2010; Livneh et al., 2010) and the Variable

37 Infiltration Capacity (VIC; Liang et al., 1996; Bowling and Lettenmaier, 2010). So-called "third 38 generation” LSMs include dynamic phenology and carbon stores, such as the Community Land 39 Model (CLM; Bonan et al., 2002; Lawrence et al., 2011). To a large extent, this advancement has 40 come as the result of three key community activities: first, the Global Land Atmosphere System 41 Study (GLASS) intercomparison studies, second, the North American and Global LDAS 42 projects, and third, the recent LandFlux initiatives. Below, we provide background on these 43 efforts, including their major findings related to evapotranspiration estimation from LSMs.

45 GLASS Intercomparison Studies: PILPS, Rhone-AGG, and GSWP

46 The international GLASS panel, as part of the Global Energy and Water Cycle Experiment 47 (GEWEX), has spearheaded three major intercomparison projects designed to evaluate the skill 
48 of land surface models for predicting water and energy fluxes and states. The first was the

49 Project to Intercompare Land-Surface Parameterization Schemes (PILPS; Henderson-Sellers et

50 al., 1995; Pitman and Henderson-Sellers 1998). This project focused on a series of evaluations

51 conducted in phases using specified atmospheric boundary conditions and parameters at points or

52 regions. One of the key findings in this project is the documentation of the systematic

53 improvements in LSMs from first-generation (bucket) to second-generation (e.g., SiB, BATS,

54 Noah, VIC) through third generation (e.g., CLM). Another major finding from PILPS is the

55 synthesis work by Koster and Milly (1997), in which it was shown that the interplay between the

56 evaporation and runoff formulations in any LSM, could be expressed via two model-independent

57 quantities: 1) the soil-depth-integrated evaporation sink efficiency and 2) the runoff-generation

58 fraction over this integrated evaporation sink. A third major finding was that hydrologically-

59 oriented models such as VIC were shown to be more skillful for continental scale water budgets.

60

61 The second major GLASS intercomparison projects, which represented a global-scale

62 follow-on to PILPS, were the Global Soil Wetness Projects (GSWPs, Dirmeyer, 2011). GSWP-

631 (Dirmeyer et. al, 1999) focused on the International Satellite Land-Surface Climatology Project

64 (ISLSCP) Initiative I forcing data for the period 1987-88, and produced the first ever global,

65 offline, multimodel land analysis based on "best possible” meteorological forcings. In addition,

66 GSWP-1 served as a pathfinder for the NLDAS and GLDAS efforts described below. GSWP-2

67 (Dirmeyer et al., 2006) built on the foundation of GSWP-1, and produced 1 degree global multi-

68 model fluxes and states for the ISLSCP II period from 1986-95 and showed that, in the absence

69 of robust in-situ and/or remotely sensed soil moisture to provide constraints, the best estimate of

70 soil wetness from multiple model products is a simple average. In addition to this finding, 
71 GSWP-2 also derived multi-model soil wetness values normalized to the LSM dynamic range

72 controlling the ET-runoff interplay, as described above in the PILPS analyses by Koster and

73 Milly (1997). With respect to ET, GSWP-2 showed that ET has the smallest interannual

74 variability of any water budget variable, and that global average transpiration is about one-third

75 larger than direct evaporation from the soil. For the GSWP-2 period, latent heat flux exceeded

76 sensible heat flux by about $20 \%$, although that may reflect an absence of soil moisture limitations

77 in later periods as observed by Jung et al. (2010) and discussed further below.

78 The third major intercomparison project, which occurred between GSWP-1 and GSWP-2, is

79 known as Rhone-AGG (Boone et al., 2004). Rhone-AGG significantly advanced the

80 community's ability to observationally diagnose deficiencies in LSM hydrological cycles by

81 looking at spatial scaling of water and energy balance processes finer than GSWP (8km vs. $1^{\circ}$ ),

82 particularly the interplay of high-elevation snow accumulation/melt and lower-elevation

83 streamflow. Techniques for evaluating and diagnosing physical processes with simulated

84 hydrographs helped advance LSM's ability to simulate the daily hydrological cycles at multiple

85 scales, most notably by implementing subgrid runoff formulations and elevation-based tiling for

86 snow pack modeling. Rhone-AGG and GSWP-2 occurred in parallel with and greatly benefitted

87 the development of NLDAS and GLDAS, as described in the following sections.

The North American Land Data Assimilation System

90 The primary goal of the North American Land Data Assimilation System (NLDAS; Mitchell

91 et al., 2004; http://ldas.gsfc.nasa.gov/nldas/; http://www.emc.ncep.noaa.gov/mmb/nldas/) is to

92 construct quality-controlled, and spatially- and temporally-consistent, land-surface model (LSM)

93 datasets from the best available observations and model outputs. NLDAS is a collaboration

94 project among several groups: NOAA/NCEP's Environmental Modeling Center (EMC), NASA's 
95 Goddard Space Flight Center (GSFC), Princeton University, the University of Washington, the

96 NOAA/NWS Office of Hydrological Development (OHD), and the NOAA/NCEP Climate

97 Prediction Center (CPC). The NLDAS project produces a LSM forcing dataset from a daily

98 gauge-based precipitation analysis (temporally disaggregated using hourly radar data, satellite

99 estimates, or other sources), bias-corrected shortwave radiation, and surface meteorology

100 reanalyses. This forcing is used to drive four separate LSMs to generate hourly model outputs of

101 surface fluxes, soil moisture, snow cover, and runoff. The current operational version of

102 NLDAS uses the following LSMs: Noah - from NOAA/NCEP, Mosaic - from GSFC, VIC -

103 from Princeton University, and SAC - from NOAA/OHD. Datasets and simulations from

104 NLDAS Phase 2 (NLDAS-2) extend back to January 1979 and continue to be produced in near

105 real-time on a 1/8th-degree grid over central North America (from 25 to $53 \mathrm{~N}$ and 125 to $67 \mathrm{~W}$ ).

106 NLDAS individual and ensemble-mean LSMs are also used for drought monitoring and as part

107 of an experimental drought forecast system. The ensemble-mean on the drought monitor is a

108 simple type of a multi-model analysis of LSMs, which have been shown to improve the depiction

109 of simulated states in many ways (e.g., Guo et al., 2007, for GSWP-2 datasets). NLDAS data

110 products are distributed at EMC as well as at the NASA Goddard Earth Sciences Data and

111 Information Services Center (GES DISC; http://disc.gsfc.nasa.gov/hydrology/).

112

113 The first incarnation of the project, Phase 1 (NLDAS-1), comprised data since October 1996

114 and consisted of a somewhat-similar yet different LSM forcing dataset (Cosgrove et al., 2003).

115 Earlier versions of the same four LSMs (Noah, SAC, VIC, and Mosaic) were used in NLDAS-1

116 as well. NLDAS-1 datasets were extensively evaluated and validated against available

117 observations in numerous studies, including examinations of the forcing (Luo et al., 2003) and of 
118 the LSM output (Robock et al., 2003). Robock et al. evaluated the LSM-simulated soil

119 moistures and temperatures against observations from the Oklahoma Mesonet, and also

120 evaluated surface latent, sensible, and ground fluxes using ARM/CART stations. They found

121 that the Noah LSM was closest to the observations of the latent heat flux in this region over a

122 two-year period. Lohmann et al. (2003) intercompared water balance and streamflow between

123 the LSMs and found regional differences up to a factor of 4 in the simulated mean annual runoff

124 and up to a factor of 2 in the mean annual evapotranspiration, with monthly differences even

125 greater. Other land parameters evaluated from NLDAS-1 included soil moisture (Schaake et al.,

126 2004), snow cover extent (Sheffield et al., 2003), and snow water equivalent (Pan et al., 2003).

127 Many of these studies from NLDAS-1 also tested the effects of LSM physics and parameter

128 changes on the evaluation results.

129

130 The NLDAS-2 forcing dataset corrects the daily gauge precipitation analysis using a PRISM

131 (Parameter-elevation Regressions on Independent Slopes; Daly et al., 1994) method which

132 considers the topographic effect on precipitation. The precipitation is temporally disaggregated

133 to hourly, primarily using Stage II radar data. In locations/times when the radar data is not

134 available, satellite retrievals, a coarser-scale hourly gauge analysis, or reanalysis data is used.

135 The non-precipitation land-surface forcing fields for NLDAS-2 are derived from the analysis

136 fields of the NCEP North American Regional Reanalysis (NARR, Mesinger et al., 2006).

137 Surface pressure, surface downward longwave radiation, and near-surface temperature and

138 humidity fields are vertically adjusted to the terrain on the NLDAS grid. The surface downward

139 shortwave radiation is bias-corrected using GOES satellite observations. NLDAS-2 also

140 contains numerous improvements to the equations of the LSMs as well as their calibration. The 
141 snow physics in the Noah LSM was upgraded (Livneh et al., 2010), VIC model parameters were

142 calibrated using streamflow observations (Troy et al., 2008), SAC used an updated potential

143 evaporation dataset (Xia et al., 2011b), and Mosaic used updated model parameters (for details,

144 see Robock et al., 2003). Xia et al. (2011a) analyzed water and energy fluxes in the upgraded

145 NLDAS-2 LSMs, including their ensemble-mean and model spread. In a separate study, Xia et

146 al. (2011c) examined the spatial distribution of the correlation between monthly-mean

147 precipitation and evapotranspiration (ET) the four LSMs; they found that the two soil vegetation

148 atmosphere transfer (SVAT) LSMs (Noah and Mosaic) had a stronger correlation, while the two

149 hydrological LSMs (VIC and SAC) had a stronger correlation between the precipitation and

150 runoff. Wei et al. (2011) evaluated improvements of the Noah LSM related to warm season

151 simulation in NLDAS by adding a seasonally- and spatially-varying LAI as well as

152 modifications to Noah's treatment of the vertical profile of root density, the minimum stomatal

153 resistance parameters, the diurnal variation of surface albedo, the roughness length for heat, and

154 the vapor-pressure and soil moisture deficit terms. This study compared the NLDAS-2 version

155 of Noah to ARM/CART latent heat flux observations and found reduced biases, which also

156 helped improve the simulation of the mean annual water balance. Mo et al. (2011) compared ET

157 from three NLDAS-2 LSMs against Ameriflux observations and found that Noah and VIC

158 tended to exhibit low ET biases in the winter, with slight high ET biases in the summer, despite

159 no apparent biases in NLDAS-2 net radiation. Mosaic generally had higher ET than the

160 observations as well as from Noah and VIC, with a three-member ensemble-mean performing

161 the best,, consistent with the findings of GSWP discussed in the previous section. Kovalskyy et

162 al. (2011) estimated evapotranspiration using a scheme that combines a water balance model

163 with an event-driven phenology model, driven with NLDAS-2 forcing; they compared these 
164 estimates against ET from the MODerate Resolution Imaging Spectroradiometer (MODIS)

165 instrument (Mu et al., 2007) as well as from the NLDAS-2 Mosaic LSM, and showed better 166 agreement to the MODIS-derived ET at the 5-km scale of the study.

The Global Land Data Assimilation System

169 The Global Land Data Assimilation System (GLDAS) led at NASA/GSFC (Rodell et al., 170 2004a) also uses satellite- and ground-based observations to construct a forcing dataset to drive 171 four LSMs. The four LSMs in GLDAS are Noah, Mosaic, VIC, and CLM, and GLDAS data 172 extends globally from January 1979 at both 1.0-degrees (all LSMs) and 0.25-degrees (Noah 173 only). In addition to extending an NLDAS-style framework to the global scale, GLDAS was one 174 of the first LDASs to routinely assimilate satellite-based surface states to improve simulated 175 water and energy fluxes and states. GLDAS has included data assimilation of MODIS snow 176 cover to constrain the modeled SWE (after Rodell and Houser, 2004), and has also studied the 177 effects of assimilating remotely-sensed skin temperatures and soil moistures. While considering 178 ET produced by GLDAS, Rodell et al. (2004b) compared basin-scale estimates of 179 evapotranspiration produced by GLDAS/Noah and other models against a water balance 180 approach using the Gravity Recovery And Climate Experiment (GRACE) satellites, and found 181 that the GRACE estimates were generally within the range of the model results, and the biases 182 were consistent and the uncertainty on the same order as GRACE.. Kato et al. (2007) examined 183 the choice of LSM, land cover, soils, elevation, and forcings using GLDAS on the simulated 184 latent and sensible heat fluxes and soil moisture compared to CEOP in situ observations. They 185 found that the LSM choice had the biggest effect on the simulated output (including ET), and 186 that ET was most sensitive first to precipitation, then land cover, and then radiation. Syed et al. 187 (2008) compared variations in terrestrial water storage from GRACE compared to GLDAS 
188 simulations and found that ET was most effective in dissipating terrestrial water storage in the

189 mid-latitudes. Despite all these detailed studies, however, none have directly evaluated both

190 GLDAS and NLDAS using observations over CONUS. One study that did compare early

191 versions of both systems (Jambor et al.,2002) demonstrated the benefit of satellite-based

192 precipitation used in conjunction with model precipitation in GLDAS while using the gauge-

193 based precipitation in NLDAS as the evaluation dataset. Overall, GLDAS's advancements in

194 land data assimilation and GRACE-based ET estimation significantly advanced the ability of

195 LSMs to estimate ET, subject to observational constraints.

196

197 The LandFlux Initiative and Reference ET Products

198 The LandFlux initiative has been coordinated by the GEWEX Radiation Panel to develop

199 and evaluate consistent and high-quality global ET datasets for climate studies. Recently

200 developed capabilities for global ET estimation using LSMs (as discussed above) as well as

201 techniques for synthesizing satellite data, flux tower data, and atmospheric reanalyses provide

202 the opportunity to produce global ET products using different approaches. The LandFlux-EVAL

203 project (Mueller et al., 2011; Jiménez et al., 2011) is currently evaluating multiple global ET

204 products produced using four different categories of techniques: 1) Observations-based

205 diagnostic datasets; 2) observationally-driven “offline” LSM products (e.g., GSWP, GLDAS); 3)

206 atmospheric reanalyses; and 4) IPCC AR4 simulations from 11 GCMs. In Mueller et al., 41

207 global land ET datasets were evaluated along with IPCC AR4 GCM simulations for the 1989-

2081995 time period. An interesting finding of a cluster analysis conducted as part of this study is

209 that the GLDAS-Noah and CLM products were closely related to two different reference ET

210 products, including the Jung et al., 2009 product described further below. 
Jiménez et al. (2011) evaluated 12 monthly mean land surface ET and other flux products for

213 the period 1993-1995 and found that the 12-product global annual mean latent heat flux (Qle)

214 was approximately $45 \mathrm{Wm}^{-2}$ with a spread of approximately $20 \mathrm{Wm}^{-2}$. Similar spreads were

215 found for sensible (Qh) and net radiative (Rn) fluxes, with larger spreads for tropical rainforest

216 year-round and grassland or crop in the dry season. Analysis for large river basins indicated

217 large spreads for the Danube, Congo, Volga, and Nile basins, with smaller spreads for other

218 basins, including the Mississippi.

220 One of the key reference datasets for the LandFlux-EVAL effort, also used as one of the

221 reference datasets in our LDAS analysis described in subsequent sections, is the Max Planck

222 Institute (MPI) flux dataset from Jung et al., (2009), which was created by synthesizing

223 FLUXNET (Baldocchi et al., 2001) tower data with meteorological forcings and vegetation

224 information from interpolated station and satellite data to produce a global, monthly, 1/2 degree

225 resolution estimate of land ET from 1982 to 2008. Jung et al. (2010) found that global annual

226 ET has been increasing by approximately $7 \mathrm{~mm}$ per year per decade during the period 1982-

227 1997, with moisture limitation eliminating this trend during the period 1998-2008. Another ET

228 product used as a reference dataset in this study is the global $1 \mathrm{~km}$ ET estimates based on MODIS

229 satellite data (Mu et al., 2011). In this dataset, ET estimates are derived using Mu et al. (2011)’s

230 algorithm, which is improved relative to the previous Mu et al. (2007) work. The ET algorithm is

231 primarily based on the Penman-Monteith equation and considers the surface energy partitioning

232 and environmental constraints to derive ET. In this study, we employ the monthly averaged

233 MOD16 ET datasets. 
Although the LandFlux-EVAL effort has compared model-based GLDAS and GSWP flux

236 estimates to observationally-based MOD16 and MPI reference flux estimates, a key question not

237 previously addressed by LandFlux-EVAL is the extent to which assimilating observed soil

238 moisture can reduce the differences between the model-based and observationally-based flux

239 estimates. Addressing this question is one of the primary motivations of the current work.

241 EXPERIMENTAL SETUP

242 To illustrate the current capability of the current LDAS systems to simulate 243 evapotranspiration at continental scales, we compare estimates from GLDAS, and two NLDAS244 equivalent simulations over the NLDAS-domain with two reference datasets: (1) the gridded 245 FLUXNET dataset from Jung et al. (2009) and (2) the MOD16 dataset developed by Mu et al. 246 (2011). Further, we also present estimates from the NLDAS-equivalent simulations that employ 247 the assimilation of satellite surface soil moisture retrievals. Because the NLDAS uses only a 248 single version of the Noah LSM, we chose to produce our NLDAS-equivalent products using the 249 Land Information System (LIS; Kumar et al., 2006, Peters-Lidard et al., 2007) with Noah 250 versions 2.7.1 and 3.2 so that we can examine the impacts of recent physics changes in Noah on 251 ET estimation. The experiments employ the same domain configuration used in the NLDAS 252 project (from $25-53^{\circ} \mathrm{N}$ and $125-67^{\circ} \mathrm{W}$ at $1 / 8^{\text {th }}$-degree resolution) and are designed in a manner as 253 similar as possible to the NLDAS-2 Noah model simulations. While the forcings and NLDAS254 equivalent simulations are at a 1/8 degree horizontal resolution, we average the outputs to $1 / 2$ 255 degree resolution prior to comparisons with the FLUXNET and MOD16 datasets. The GLDAS 256 Noah datasets are similarly averaged from $1 / 4$-degree to the $1 / 2$ degree resolution. The forcing for 257 the NLDAS-equivalent runs is the NLDAS-2 described above. The simulations are run with a 15 
258 minute timestep, and the models are spun up by running from 1979 to 1985 and then

259 reinitializing the model from 1979 to generate outputs from 1979-2010.

260

261 In the data assimilation integrations, we employ surface soil moisture data derived from the

262 Advanced Microwave Scanning Radiometer for the Earth Observing System (AMSR-E) sensor

263 aboard the Aqua satellite. Two different AMSR-E retrieval products are employed in the data

264 assimilation simulations; (1) the NASA Level-3, “AE_Land3” product (version 6, Njoku et al.,

265 2003) and (2) AMSR-E Land Parameter Retrieval Model (LPRM) product developed at NASA

266 GSFC and VU Amsterdam (Owe et al., 2008). The NASA product is primarily based on X-band

267 brightness temperatures, whereas both X-band and C-band brightness temperature-based

268 retrievals are used in the LPRM product. Measurements from both ascending and descending

269 overpasses are used in these products. A number of quality control measures are applied to the

270 soil moisture retrievals prior to data assimilation, similar to the approaches followed in Reichle

271 et al. (2007) and Liu et al. (2011). In the soil moisture products, retrievals flagged for dense

272 vegetation, precipitation, snow cover, frozen ground, and Radio Frequency Interference (RFI)

273 are excluded in the assimilation system. Further, additional quality control is applied based on

274 the information from the land surface model, where the retrievals are excluded when the land

275 surface model indicated active precipitation, non-zero snow cover, frozen soil or dense 276 vegetation (when green vegetation fraction > 0.7).

278 The assimilation integrations employ a one-dimensional Ensemble Kalman Filter (EnKF) 279 algorithm, which is a widely used technique for soil moisture data assimilation (Reichle et al., 280 2002, Crow and Wood, 2003, Reichle et al., 2007, Kumar et al., 2008, Kumar et al., 2009). An 
281 ensemble size of 12 is used in these simulations (Kumar et al., 2008), with perturbations applied

282 to both the meteorological fields and model prognostic fields to simulate uncertainty in the soil

283 moisture fields. The parameters used for these perturbations are listed in Table 1, which are

284 based on earlier data assimilation studies (Kumar et al., 2009). As algorithms such as EnKF are

285 designed to correct random, zero-mean errors and assume the use of unbiased observations

286 relative to the model generated background, it is often a common practice to scale the

287 observations prior to data assimilation to match the model's climatology (Reichle and Koster,

288 2004, Drusch et al., 2005, Reichle et al., 2007, Kumar et al., 2009). Here we employ the

289 Cumulative Distribution Function (CDF)-scaling approach of Reichle and Koster (2004), where

290 the observations (roughly corresponding to a maximum depth of $2 \mathrm{~cm}$ ) are rescaled to the

291 model's $10 \mathrm{~cm}$ surface soil moisture climatology by matching the CDF of the observations to the

292 CDF of the model soil moisture. The model CDF and observation CDF are computed using 7

293 years of data (2002-2008), separately for each grid point.

295 As the soil moisture retrievals are available only from 2002 onwards, the NLDAS-equivalent 296 simulations with data assimilation are conducted during the period of 2002-2008. During this

297 period, we update not only the surface $(10 \mathrm{~cm})$ soil moisture in Noah, but also the layer 2 through

298 layer 4 soil moisture, following the parameters in Table 1 . The comparisons presented in next 299 section are limited to the data assimilation period (2002-2008).

301 CURRENT RESEARCH FINDINGS AND FUTURE WORK

302 The results presented in this section focus first on the evaluation of the LDAS ET estimates 303 that do not employ data assimilation. This is followed by the description of the impact of soil 304 moisture data assimilation on ET estimation. 


\section{Evaluation of the ET estimates from LDAS simulations}

307 Table 2 presents the domain-averaged root mean square and bias errors and the associated 95\%

308 confidence intervals, for latent (Qle) and sensible (Qh) heat flux estimates from the three LDAS

309 simulations compared against the gridded FLUXNET and MOD16 datasets. This table also

310 shows results from the data assimilation experiments to be discussed in the next section.

311 Overall, the NLDAS-like simulation using the Noah 2.7.1 model provides better estimates of Qle

312 (RMSE of $19.3 \mathrm{Wm}^{-2}$ against FLUXNET and $21.5 \mathrm{Wm}^{-2}$ against MOD16) relative to other

313 products. Average seasonal cycles of these error metrics stratified monthly are presented in

314 Figure 2. In both sets of comparisons, the largest differences between the LDAS simulations are

315 observed during the spring and fall months, with NLDAS-like simulations with Noah 2.7.1

316 providing the better estimates. Qle estimates from GLDAS show underestimation in the late

317 summer and fall months and an overestimation in the spring and early summer months, relative

318 to both reference datasets. Comparatively, NLDAS-like integration with Noah 2.7.1 indicates

319 lower biases most months, but the biases are consistently positive. Though Noah 3.2 is a newer

320 version of the Noah model, the flux estimates appear to be degraded overall relative to Noah

321 2.7.1, with the comparison against FLUXNET data indicating more severe degradations relative

322 to the MOD16. This may reflect uncertainty in the reference flux datasets during the springtime,

323 in particular. During the fall months, bias estimates in Noah 3.2 are improved relative to Noah

324 2.7.1 (in the comparisons against FLUXNET), but during spring and summer months, biases in

325 Noah 3.2 ET increase compared to that of Noah 2.7.1. It can be noted that these trends in RMSE

326 and bias errors are highly statistically significant, as indicated by the $95 \%$ confidence interval

327 values given for each error estimate. Note that any spatial auto-correlation of RMSE and Bias

328 values across the domain is ignored in computing these confidence intervals. The tight intervals 
329 reported in Table 2 are likely to increase if allowances for spatial autocorrelation of errors are

330 included in the confidence interval computations. The trend of increased flux error estimates in

331 Noah 3.2 relative to Noah 2.7.1 is likely a result of the changes in model parameters (such as

332 LAI) along with other changes to Noah's warm season physics as described in Wei et al. (2011).

333 As discussed in the Background section, Wei et al. (2011) showed improvement of these physics

334 changes when compared to ARM/CART flux datasets, whereas our analysis uses gridded data

335 (FLUXNET and MOD16) over the entire NLDAS domain, including many different vegetation

336 types and climate regimes. Other studies (also presented in the Background section) showed

337 Noah 3.2's improved simulation of streamflow, snow, and other hydrologic variables relative to

338 Noah 2.7.1.

340 Figure 3 provides an intercomparison of the seasonally-averaged Qle computed using 341 estimates from three consecutive months (DJF represents December-January-February, MAM 342 represents March-April-May, JJA represents June-July-August and SON represents September-

343 October-November) from the three LDAS integrations and the two reference datasets, the 344 gridded FLUXNET and MOD16 product. Relative to FLUXNET, all three LDAS datasets show 345 higher ET in the spring MAM months in the Southeast and Lower Mississippi River Basin. 346 During JJA, however, GLDAS compares much better than the NLDAS-like Noah simulations. 347 Interestingly, the Noah 2.7.1 and Noah 3.2 results for JJA are generally similar except over 348 highly vegetated crop regions in the upper Midwest and the irrigated growing areas along the 349 Mississippi River. Neither reference dataset seems to reflect irrigated areas (see, for example 350 Table 4 in $\mathrm{Mu}$ et al., 2011), and the differences in Noah2.7.1 and Noah3.2 do not include 351 irrigation effects, so these differences for crops are likely due to changes in the aerodynamic 
352 conductance formulation in Noah, implemented primarily for improved snowmelt modeling.

353 Here, the Noah 3.2 JJA Qle is much higher, indicating that the parameter values used for the

354 vegetation type(s) in these regions may need refinement. A closer look during MAM also shows

355 this same pattern with higher Qle in Noah 3.2 relative to Noah 2.7.1. It can be noted that except

356 MOD16, all other datasets show an artifact of lower Qle in California and West Coast regions.

357 Interestingly, the higher Qle areas for MOD16 do not seem to correspond to known irrigated

358 areas. During the fall SON months, the Qle from GLDAS is low compared to FLUXNET,

359 particularly over the Upper Plains and Southeast; the Noah simulations show a pattern overall

360 much closer to FLUXNET, but with too high Qle magnitudes right along the Gulf Coast.

361 MOD16, on the other hand, indicates lower Qle over the High plains consistent with GLDAS,

362 and higher Qle over the Southeast, consistent with the NLDAS-based estimates.

363

\section{Impact of soil moisture data assimilation on ET estimates}

365 Figure 4 provides a comparison of the average seasonal cycles of RMSE and Bias in Qle

366 estimates (again, relative to the two reference datasets) from the NLDAS-like simulation without

367 any data assimilation (termed as the "open loop" (OL) simulation) and the two integrations that

368 employ the assimilation of surface soil moisture retrievals from NASA and LPRM products

369 (NASA-DA and LPRM-DA, respectively). In this comparison, all three model integrations

370 employ Noah 3.2. It can first be observed that the assimilation of soil moisture retrievals impact

371 the Qle estimates, primarily during the summer and fall months. The Qle estimates from the open

372 loop simulation are systematically improved by the assimilation of LPRM soil moisture

373 retrievals, whereas the assimilation of NASA retrievals shows degradation. Compared to

374 FLUXNET, the domain averaged RMSE of the open loop integration is $27.6 \mathrm{Wm}^{-2}$ and it

375 increases to $29.4 \mathrm{Wm}^{-2}$ in the NASA-DA integration (Table 2). The improvements shown in 
376 Figure 4 from LPRM-DA translates to a domain averaged RMSE of $25.6 \mathrm{Wm}^{-2}$ when compared

377 to FLUXNET. The trends in RMSE and Bias are similar in the comparisons against MOD16.

378 The RMSE of the open loop integration is $22.7 \mathrm{Wm}^{-2}$ and it improves to $21.9 \mathrm{Wm}^{-2}$ with the

379 assimilation of LPRM soil moisture retrievals. The assimilation of NASA soil moisture retrievals

380 degrades the ET estimates, with a domain averaged RMSE of $24.5 \mathrm{Wm}^{-2}$.

To quantify the spatial improvements due to assimilation, we define an "improvement metric" as difference between the RMSE of the integration with data assimilation and the RMSE

384 of the open loop integration (RMSE (DA) - RMSE (OL)). If data assimilation improves the flux estimates (i.e., reduces the RMSE), then the improvement metric will be negative. On the other

386 hand, the improvement metric will be positive if the assimilation simulation degrades the flux 387 estimates. Figures 5 and 6 present a comparison of the improvement metric stratified seasonally, 388 from both assimilation integrations, as compared to both reference ET datasets. Figure 5 389 represents the improvement metric when using the NASA AMSR-E product and Figure 6 shows 390 the corresponding comparisons when using the LPRM product. In both sets of comparisons, the 391 LPRM-based assimilation provides more systematic improvements in the flux estimates, whereas 392 the NASA-based integration indicates degradations over several regions. For example, during 393 MAM months, the flux estimates from NASA-DA show degradation over the Southern Great 394 Plains, with improvements observed over Illinois, Indiana, Ohio and areas along the Mississippi 395 river; these are the same areas discussed earlier in Figure 3 where Noah 3.2 had higher simulated 396 ET. The LPRM-integration on the other hand, shows improvements over large areas of 397 Midwest, and South-central U.S during MAM, with no significant degradations observed as a 398 result of soil moisture assimilation. During JJA, the NASA-DA shows degradations in most 
regions interspersed with improvements over a few regions near North Dakota, Illinois, Eastern

400 Texas and the West coast, in the comparisons using the FLUXNET data. The MOD16-based

401 comparisons show similar results, with small regions of improvements over the Central and

402 Eastern US with degradations over most of the domain. In contrast, the JJA comparisons for

403 LPRM-DA show degradations in a few regions only, with improvements observed over large

404 areas of the Midwest U.S. During the SON months, similar trends are seen, with degradations

405 over Mexico and regions near Ohio and Illinois (when compared to FLUXNET) and Mississippi

406 river basin areas (when compared to MOD16). The LPRM-DA based simulations show

407 improvements over Midwest and Central US in the comparisons against MOD16 and no

408 significant degradations in the comparisons against FLUXNET.

409 Further analysis of the differences shown in Figures 5 and 6 reveals that the magnitudes of 410 the differences are strongly related to landcover type. Based on further analysis (not shown),

411 stratifying the Qle RMSE improvements due to DA with respect to landcover type, we found that

412 the most significant improvements occur in croplands for both soil moisture datasets and both

413 reference datasets. Grassland was also found to have significant changes in Qle RMSE with both

414 datasets, and more so with respect to the MOD16 reference data. In general, DA does not occur

415 over heavily vegetated regions, due to masking out high-vegetation water content areas which

416 make soil moisture retrievals difficult. Nonetheless, our results suggest modest changes over 417 evergreen needleleaf forests and woodlands, especially for the NASA product.

419 In order to relate the improvements and degradations in latent heat flux estimates to changes 420 in soil moisture resulting from data assimilation, we present a comparison of the surface soil 421 moisture difference maps in Figure 7. The difference maps represent the mean surface soil 
422 moisture of the data assimilation integration subtracted by the mean surface soil moisture of the

423 open loop integration. In other words, the difference maps represent the changes in soil moisture

424 values introduced by data assimilation, averaged seasonally. A negative difference indicates that

425 the soil moisture is drier due to assimilation and a positive difference indicates that the soil

426 moisture is wetter from assimilation. By comparing Figures 5 and 6 against Figure 7, it can be

427 observed that the spatial patterns of the improvement metric correlates well with those of the soil

428 moisture difference maps. For example, during MAM, both the NASA-DA and the NASA-

429 LPRM (with a smaller magnitude) soil moisture difference maps indicate drier patterns over

430 Illinois, Indiana, Ohio and areas along the Mississippi river that leads to corresponding

431 improvements in latent flux estimates (Figure 5) over these same regions. During JJA, the soil

432 moisture changes due to assimilation of NASA and LPRM are generally of opposite sign, and

433 seem to show a mix of improvements and degradations in the fluxes, depending on landcover. .

434 During SON, assimilation of NASA retrievals dries the soil moisture over Lower Texas and

435 Mexico (relative to OL) and it leads to a corresponding degradation in the flux estimates over

436 these regions when compared to FLUXNET (Figure 5, panel for SON). Similar patterns of tight

437 correlation between the soil moisture difference patterns and the flux improvement patterns can

438 be observed in the LPRM-DA integration. During JJA, over the Midwest US, the LPRM-DA

439 causes the soil moisture simulations to be drier than the open loop simulation leading to

440 improvements in the latent heat flux estimates over the same areas.

442 It is important to note that the CDF-scaling approach for data assimilation used here (and 443 described previously) is intended to preserve the soil moisture climatology of the LSM, while 444 taking advantage of observed anomalies. Therefore, the results suggest that the 
445 improvements/degradations in Qle due to soil moisture assimilation are a direct result of 446 improved/degraded soil moisture stress responses in the stomatal resistance formulation of the 447 Noah 3.2 LSM. This sort of non-linear feedback is likely due to the ability of LPRM-DA to 448 redistribute water in a seasonal cycle that corresponds to Noah's biases in soil moisture and ET. 449 By design, and verified by us (not shown) the soil moisture increments from both NASA-DA and 450 LPRM-DA do not change the mean surface soil moisture relative to the open loop. However, as 451 most easily explained via the bias time series in Figure 4, significant seasonal changes in soil 452 moisture, translate into varying ET responses. In winter, the change in ET from the OL to the 453 DA is nominal (since Rnet, and therefore Qle is small). In spring, LPRM tends to reduce soil 454 moisture relative to the open loop and therefore Qle bias while NASA-DA increases soil 455 moisture and Qle bias. In the summer, the open loop skill is higher, and both products further 456 compensate for errors, with LPRM tending to overdry and NASA tending too wet. Overall, the 457 net effect is a domain-averaged increase of $2 \mathrm{Wm}^{-2}$ in total Qle for the LPRM-DA, and a $3 \mathrm{Wm}^{-2}$ 458 reduction in Qle for NASA-DA.

\section{Evaluation of the surface energy partition from LDAS simulations}

461 The surface energy partition consists of two key components, the latent heat and the sensible 462 heat fluxes. Though the primary focus of this article is to evaluate the latent heat estimates, we 463 also evaluated the sensible heat flux (Qh) estimates from the LDAS simulations using 464 FLUXNET data to examine if the trends seen in the Qle estimates are consistent for both energy 465 partition terms. Trends in error metrics similar to those seen with latent heat flux estimates are 466 found in the sensible heat estimates. As shown in Table 2, Qh estimates from GLDAS has a 467 domain averaged RMSE of 23.4 $\mathrm{Wm}^{-2}$ whereas the NLDAS-like simulations with Noah 2.7.1 468 and Noah 3.2 have domain averaged RMSEs of 21.1 and $32.5 \mathrm{Wm}^{-2}$, respectively. The 
469 assimilation with LPRM data improves the domain averaged RMSE to $30.4 \mathrm{Wm}^{-2}$ (over that of

470 the open loop integration NLDAS-like simulation with Noah 3.2), whereas the assimilation of

471 NASA retrievals degrades the sensible heat flux estimates with a domain averaged RMSE of

$47234.5 \mathrm{Wm}^{-2}$. Spatial patterns of improvements and degradations similar to that seen in Figures 5

473 and 6 are observed for sensible heat fluxes as well (not shown; for FLUXNET only, as Qh is not

474 available from MOD16). Again, these trends are statistically significant, as seen from the 475 confidence interval values presented in Table 2.

476

\section{SUMMARY}

478 This article provides a description of the capabilities of Land Data Assimilation Systems (LDAS)

479 for generating ET estimates and presents a quantitative evaluation of ET estimates, expressed as 480 latent heat flux (Qle), from a number of LDAS simulations. The simulated ET values from 481 GLDAS and LSM simulations conducted over the NLDAS-domain using two different versions 482 of the Noah land surface model (Noah version 2.7.1 and version 3.2) are compared against two 483 reference ET datasets: the gridded tower-based estimates from the FLUXNET measurements and 484 ET estimates based on MODIS satellite data, known as the MOD16 product. The article also 485 presents an evaluation of the impact of soil moisture data assimilation in ET estimation. The data 486 assimilation integrations employ two different retrievals of the AMSR-E soil moisture 487 measurements; the NASA Level-3 product and the AMSR-E Land Parameter Retrieval Model 488 product from VU Amsterdam.

490 The evaluation of ET fields indicate that the simulation using NLDAS forcing with Noah 491 2.7.1 provides slightly better estimates among the LDAS simulations without data assimilation, 492 although all Noah simulations suffer from significant high biases relative to the two reference 
493 dataset. This could be due to a combination of parameter and structural errors in addition to

494 errors in the reference data themselves. The three LDAS simulations differ most during the 495 spring and fall months. Comparison of the seasonally averaged ET fluxes show overestimations 496 during MAM in all three LDAS products over the Southeast and Lower Mississippi River basin. 497 During JJA, the differences between the two Noah model-based simulations are more prominent 498 over vegetated crop regions in the upper Midwest and irrigated areas along the Mississippi river. 499 GLDAS product shows underestimation in ET during the SON months, whereas the NLDAS500 forced Noah simulations show better agreement with both FLUXNET and MOD16 estimates 501 during this period.

502

503 The assimilation of surface soil moisture impacts the ET estimates, particularly during the spring 504 (MAM) and summer (JJA) months, which is when the expected impacts would be largest due to 505 increasing soil moisture stress, insolation, and vegetation fraction conditions. The assimilation of 506 LPRM retrievals demonstrates systematic, statistically significant but modest improvements in 507 ET estimates relative to the Noah model simulation without data assimilation. The assimilation 508 of NASA retrievals, on the other hand, provides mixed results, with improvements in a few 509 regions of the NLDAS-domain. Overall, the integration using the NASA soil moisture retrievals 510 indicates degradation of the open loop ET estimates. The results also indicate strong correlations 511 between the improvements/degradations of ET estimates and the changes in soil moisture fields 512 introduced by soil moisture assimilation. Finally, the analysis of the sensible heat flux estimates 513 indicates consistent trends in both surface energy partition terms (latent and sensible estimates). 


\section{Acknowledgements}

516 We gratefully acknowledge the financial support from the NASA Earth Science Technology

517 Office (ESTO) (Advanced Information System Technology program award AIST-08-077), the

518 NASA Energy and Water Cycle Study (NEWS), the Air Force Weather Agency, and NOAA's

519 Climate Program Office. The efforts of NLDAS participants in generating the surface forcing is

520 greatly appreciated. Some of the data used in this effort were acquired as part of the activities of

521 NASA's Science Mission Directorate, and are archived and distributed by the Goddard Earth

522 Sciences (GES) Data and Information Services Center (DISC). Computing was supported by the

523 resources at the NASA Center for Climate Simulation.

524

525 


\section{REFERENCES}

527 Baldocchi, D., et al., 2001; FLUXNET: A new tool to study the temporal and spatial variability of ecosystem-scale carbon dioxide, water vapor, and energy flux densities, Bull. Am. Meteorol. Soc., 82(11), 2415-2434.

Barlage, M., F. Chen, M. Tewari, K. Ikeda, D. Gochis, J. Dudhia, R. Rasmussen, B. Livneh, M. Ek, and K. Mitchell, 2010: Noah land surface model modifications to improve snowpack prediction in the Colorado Rocky Mountains, J. Geophys. Res., 115, D22101, doi:10.1029/2009JD013470.

Bonan, G. B., K. W. Oleson, M. Vertenstein, S. Levis, X. Zeng, Y. Dai, R. E. Dickinson, Z-L. Yang, 2002: The land surface climatology of the community land model coupled to the NCAR community climate model, J. Clim., 15 (22), 3123-3149.

Boone, A., F. Habets, J. Noilhan, E. Blyth, D. Clark, P. Dirmeyer, Y. Gusev, I. Haddeland, R. Koster, D. Lohmann, S. Mahanama, K. Mitchell, O. Nasanova, G.-Y. Niu, A. Pitman, J. Polcher, A. B. Shmakin, K. Tanaka, B. van den Hurk, S. Verant, D. Verseghy, and P. Viterbo, 2004: The Rhône-aggregation land surface scheme intercomparison project: An overview. J. Climate, 17, 187-208, doi: 10.1175/15200442(2004)017<0187:TRLSSI >2.0.CO;2.

Bowling, L.C. and D.P. Lettenmaier, 2010: Modeling the effects of lakes and wetlands on the water balance of Arctic Environments, J. Hydromet., 11, 276-295, doi: 10.1175/2009JHM1084.1.

Cosgrove, B.A., D. Lohmann, K.E. Mitchell, P.R. Houser, E.F. Wood, J. Schaake, A. Robock, C. Marshall, J. Sheffield, L. Luo, Q. Duan, R.T. Pinker, J.D. Tarpley, R.W. Higgins, and J. Meng, 2003: Real-time and retrospective forcing in the North American Land Data 
Assimilation System (NLDAS) project. J. Geophys. Res., 108(D22), 8842, doi:10.1029/2002JD003118.

551 Crow, W.T. and E.F. Wood, 2003: The assimilation of remotely sensed soil brightness temperature imagery into a land surface model using ensemble kalman filtering: A case study based on ESTAR measurements during SGP97. Advances in Water Resources, 26, 137-149.

Dai, Y., X. Zeng, R.E. Dickinson, I. Baker, G.B. Bonan, M.G. Bosilovich, A.S. Denning, P.A. Dirmeyer, P.R. Houser, G.-Y. Niu, K.W. Oleson, C.A. Schlosser and Z.-L. Yang, 2003: The Common Land Model (CLM), Bull. Amer. Meteor. Soc., Vol. 84, No. 8, 1013-1024.

Daly, C., R.P. Neilson, and D.L. Phillips, 1994: A statistical-topographic model for mapping climatological precipitation over mountainous terrain. J. Appl. Meteor., 33, 140-158, doi: 10.1175/1520-0450(1994)033<0140:ASTMFM>2.0.CO;2.

Dickinson, R. E., A. Henderson-Sellers, P. J. Kennedy, and M. F. Wilson, 1986: Biosphereatmosphere transfer scheme (BATS) for the NCAR Community Climate Model. Tech. Note TN-275+STR, 69 pp.

Drusch, M., 2007: Initializing numerical weather prediction models with satellite derived surface soil moisture: Data assimilation experiments with ECMWF's integrated forecast system and the TMI soil moisture dataset. J. Geophys. Res., 112, D03102, doi:10.1029/2006JD007478.

Dirmeyer, P. A., 2011: A history of the Global Soil Wetness Project (GSWP). J. Hydrometeor., 569 (in press), doi: 10.1175/JHM-D-10-05010.1. 
570 Dirmeyer, Paul A., A. J. Dolman, Nobuo Sato, 1999: The Pilot Phase of the Global Soil Wetness

571

572

573

574

575

576

577

578

579

580

581

582

583

584

585

586

587

588

589

590

591

592

Project. Bull. Amer. Meteor. Soc., 80, 851-878, doi: 10.1175/15200477(1999)080<0851:TPPOTG>2.0.CO;2

Dirmeyer, Paul A., Xiang Gao, Mei Zhao, Zhichang Guo, Taikan Oki, Naota Hanasaki, 2006: GSWP-2: Multimodel Analysis and Implications for Our Perception of the Land Surface. Bull. Amer. Meteor. Soc., 87, 1381-1397, doi: 10.1175/BAMS-87-10-1381.

Ek, M. B., K. E. Mitchell, Y. Lin, E. Rogers, P. Grunmann, V. Koren, G. Gayno, and J. D. Tarpley, (2003), Implementation of Noah land-surface model advances in the NCEP operational mesoscale Eta model, J. Geophys. Res., 108(D22), 8851, doi: 10.1029/2002JD003296.

Guo, Z., P. A. Dirmeyer, X. Gao, and M. Zhao, 2007: Improving the quality of simulated soil moisture with a multi-model ensemble approach. Quart. J. Roy. Meteor. Soc., 133, 731747.

Henderson-Sellers, A., A. J. Pitman, P. K. Love, P. Irannejad, and T. H. Chen, 1995: The Project for Intercomparison of Land Surface Parameterization Schemes (PILPS): Phases 2 and 3. Bull. Amer. Meteor. Soc., 76, 489-503.

Jambor, U., P.R. Houser, M. Rodell, et al., 2002: Remotely sensed forcing data and the Global Land Data Assimilation System. IEEE International Geoscience and Remote Sensing Symposium (IGARSS 2002)/24th Canadian Symposium on Remote Sensing, 24-28 Jun 2002, Toronto, Canada; Vols. I-VI, Proceedings - Remote Sensing: Integrating Our View of the Planet, pp. 1405-1407.

Jiménez, C., et al., 2011; Global intercomparison of 12 land surface heat flux estimates, J. Geophys. Res., 116, D02102, doi:10.1029/2010JD014545. 
Jung, M., M. Reichstein, and A. Bondeau, 2009: Towards global empirical upscaling of FLUXNET eddy covariance observations: validation of a model tree ensemble approach using a biosphere model, Biogeosciences, 6, 2001-2013.

Jung, M., M. Reichstein, P. Ciais, S.I.Seneviratne, J. Sheffield, M.L. Goulden, G. Bonan, A. Cescatti, J. Chen, R. de Jeu, A. Johnanes Dolman, W. Eugster, D. Gerten, D. Gianelle, N. Gobron, J. Heinke, J. Kimball, B. E. Law, L. Montagnani, Q. Mu, B. Mueller, K. Oleson, D. Papale, A.D. Richardson, O. Roupsard, S. Running, E. Tomelleri, N. Viovy, U. Weber, C. Williams, E. Wood, S. Zaehle and K. Zhang, 2010: Recent decline in the global land evaportranspiration trend due to limited moisture supply, Nature, doi:10.1038/nature09396.

Kato, H., M. Rodell, F. Beyrich, H. Cleugh, E. van Gorsel, H. Liu, and T.P. Meyers, 2007: Sensitivity of land surface simulations to model physics, land characteristics, and forcings at four CEOP sites. J. Meteor. Soc. Japan, 85A, 187-204.

Koster, R. D., and P. C. D. Milly, 1997: The interplay between transpiration and runoff formulations in land surface schemes used with atmospheric models. J. Climate, 10, $1578-1591$.

Kovalskyy, V., G.M. Henebry, B. Adusei, M. Hansen, D.P. Roy, and D.M. Mocko, 2011: Spatially explicit comparison and performance assessment of an event driven phenology model coupled with VegET evapotranspiration model. To be submitted to J. Geophys. Res.

Kumar, S. V., C. D. Peters-Lidard, Y. Tian, J. Geiger, P. R. Houser, S. Olden, L. Lighty, J. L. Eastman, P. Dirmeyer, B. Doty, J. Adams, E. Wood and J. Sheffield, 2006: LIS - An 

Modeling and Software, 21, 1402-1415.

617 Kumar, S.V., R. H. Reichle, C. D. Peters-Lidard, R. Koster, X. Zhan, W. Crow, J. Eylander, and

Kumar, S.V., R.H. Reichle, R.Koster, W.T. Crow, and C.D. Peters-Lidard, 2009: Role of subsurface physics in the assimilation of surface soil moisture observations, Journal of Hydrometeorology, doi:10.1175/2009JHM1134.1.

Lawrence, D.M., K.W. Oleson, M.G. Flanner, P.E. Thornton, S.C. Swenson, P.J. Lawrence, X. Zeng, Z.-L. Yang, S. Levis, K. Sakaguchi, G.B. Bonan, and A.G. Slater, 2011: Parameterization improvements and functional and structural advances in version 4 of the Community Land Model. J. Adv. Model. Earth Sys., 3, DOI: 10.1029/2011MS000045.

Livneh, B., Y. Xia, K. E. Mitchell, M. B. Ek, and D. P. Lettenmaier, 2010: Noah LSM Snow Model Diagnostics and Enhancements, J. Hydromet., 11, 721-738.

Liang, X., E. F. Wood, and D. Lettenmaier, Surface and soil moisture parameterization of the VIC-2L model: Evaluation and modifications, 1996: Global Planet. Change, 13, 195-206.

Liu, Q., R.H. Reichle, R. Bindlish, M.H. Cosh, W.T. Crow, R. de Jeu, G.J.M. De Lannoy, G.J. Huffman, T.J. Jackson, 2011: The contributions of precipitation and soil moisture observations to the skill of soil moisture estimates in a land data assimilation system, Journal of Hydrometeorology, doi:10.1175/JHM-D-10.05000.

Livneh, B, Y. Xia, K.E. Mitchell, M.B. Ek, and D. Lettenmaier, 2010: Noah LSM snow model diagnostics and enhancements. J. Hydrometeor., 11, 721-738. 
Lohmann, D., K.E. Mitchell, P.R. Houser, E.F. Wood, J.C. Schaake, A. Robock, B.A. Cosgrove, J. Sheffield, Q. Duan, L. Luo, W. Higgins, R.T. Pinker, and J.D. Tarpley, 2004: Streamflow and water balance intercomparisons of four land surface models in the North American Land Data Assimilation System project. J. Geophys. Res., 109, D07S91, doi:10.1029/2003JD003517.

Luo, L., A. Robock, K.E. Mitchell, P.R. Houser, E.F. Wood, J.C. Schaake, D. Lohmann, B.A. Cosgrove, F. Wen, J. Sheffield, Q. Duan, R.W. Higgins, R.T. Pinker, and J.D. Tarpley, 2003: Validation of the North American Land Data Assimilation System (NLDAS) retrospective forcing over the southern Great Plains. J. Geophys. Res., 108(D22), 8843, doi:10.1029/2002JD003246.

Manabe, S., 1969: Climate and the circulation. I. The atmospheric circulation and the hydrology of the earth’s surface. Mon. Wea. Rev., 97, 739-774.

Mesinger, F., G. DiMego, E. Kalnay, K.E. Mitchell, P.C. Shafran, W. Ebisuzaki, D. Jovic, J. Woollen, E. Rogers, E.H. Berbery, M.B. Ek, Y. Fan, R. Grumbine, W. Higgins, H. Li, Y. Lin, G. Manikin, D. Parrish, and W. Shi., 2006: North American Regional Reanalysis. Bull. Amer. Meteor. Soc., 87, 343-360.

Mitchell, K.E., D. Lohmann, P.R. Houser, E.F. Wood, J.C. Schaake, A. Robock, B.A. Cosgrove, J. Sheffield, Q. Duan, L. Luo, R.W. Higgins, R.T. Pinker, J.D. Tarpley, D.P. Lettenmaier, C.H. Marshall, J.K. Entin, M. Pan, W. Shi, V. Koren, J. Meng, B. H. Ramsay, and A.A. Bailey, 2004: The multi-institution North American Land Data Assimilation System (NLDAS): Utilizing multiple GCIP products and partners in a continental distributed hydrological modeling system. J. Geophys. Res., 109, D07S90, doi:10.1029/2003JD003823. 
Mo, K.C., L.N. Long, Y. Xia, S.K. Yang, J.E. Schemm, and M. Ek, 2011: Drought Indices Based on the Climate Forecast System Reanalysis and Ensemble NLDAS. J. Hydrometeor., 12(2), 181-205, doi:10.1175/2010JHM1310.1.

Mu, Q., F.A. Heinsch, M. Zhao, and S. Running, 2007: Development of a global evapotranspiration algorithm based on MODIS and global meteorology data, Remote Sensing of Environment, 111(4), 519-536.

Mu, Q., M. Zhao, S.W. Running, 2011: Improvements to a MODIS Global Terrestrial Evapotranspiration Algorithm, Remote Sensing of Environment, in press.

Mueller, B., et al., 2011: Evaluation of global observations-based evapotranspiration datasets and IPCC AR4 simulations, Geophys. Res. Lett., 38, L06402, doi:10.1029/2010GL046230.

National Research Council, 2011: Global Change and Extreme Hydrology: Testing Conventional Wisdom. Washington, DC: National Academies Press, 60pp.

National Research Council, 2010: Assessment of Intraseasonal to Interannual Climate Prediction and Predictability. Washington, DC: National Academies Press, 192pp.

Njoku, E.G., T.L. Jackson, V. Lakshmi, T.Chan, and S.V. Nghiem, 2003: Soil moisture retrieval from AMSR-E, IEEE Transactions on Geoscience and Remote Sensing, 41 (2): 215-229.

Owe, M., R.A.M. de Jeu, and T.R. H. Holmes, 2008: Multi-sensor historical climatology of satellite-derived global land surface moisture, J. Geophys. Res. 13, F01002, doi:1029/2007JF000769.

Pan, M., P. Ming, J. Sheffield, E.F. Wood, K.E. Mitchell, P.R. Houser, J.C. Schaake, A. Robock, D. Lohmann, B. Cosgrove, Q. Duan, L. Luo, R.W. Higgins, R.T. Pinker, and J.D. Tarpley, 2003: Snow process modeling in the North American Land Data Assimilation 
System (NLDAS): 2. Evaluation of model simulated snow water equivalent. J. Geophys. Res., 108(D22), 8850, doi:10.1029/2003JD003994.

Peters-Lidard, C.D., P.R. Houser, Y. Tian, S.V. Kumar, J.V. Geiger, S. Olden, L. Lighty, J.L. 2007: High-performance earth system modeling with NASA/GSFC’s Land Information System, Innovations in Systems and Software Engineering, 3(3), 157-165.

Pitman, A. J., and A. Henderson-Sellers, 1998: Recent progress and results from the Project for

Reichle, R.H., D. M. McLaughlin, and D.A. Entekhabi, 2002: Hydrologic data assimilation with the ensemble Kalman filter, Monthly Weather Review, 130, 1, 103-114.

Reichle, R.H. and R Koster, 2004: Bias reduction in short records of satellite soil moisture,

Reichle, R.H., R.D. Koster, P. Liu, S.P.P. Mahanama, E.G. Njoku, and M. Owe, 2007: Geophys. Res. Lett. L19501,doi:10.1029/2004GL020938. Comparison and assimilation of global soil moisture retrievals from the Advanced Microwave Scanning Radiometer for the Earth Observing System (AMSR-E) and the Scanning Multichannel Microwave Radiometer (SMMR), J. Geophys. Res., 112, D09108, doi:10.1029/2006JD008033.

Robock, A., L. Luo, E.F. Wood, F. Wen, K.E. Mitchell, P.R. Houser, J.C. Schaake, D. Lohmann, B. Cosgrove, J. Sheffield, Q. Duan, R.W. Higgins, R.T. Pinker, J.D. Tarpley, J.B. Basara, and K.C. Crawford, 2003: Evaluation of the North American Land Data Assimilation System over the southern Great Plains during the warm season. J. Geophys. Res., 108(D22), 8846, doi:10.1029/2002JD003245. 
Rodell, M., P.R. Houser, U. Jambor, J. Gottschalck, K. Mitchell, C.-J. Meng, K. Arsenault, B. Cosgrove, J. Radakovich, M. Bosilovich, J.K. Entin, J.P. Walker, D. Lohmann, and D. Toll, 2004a The Global Land Data Assimilation System. Bull. Amer. Meteor. Soc., 85(3), 381-394.

711 Rodell, M., J.S. Famiglietti, J. Chen, S. Seneviratne, P. Viterbo, S. Holl, and C. R. Wilson, 2004b: Basin scale estimates of evapotranspiration using GRACE and other observations.

Rodell, M., and P.R. Houser, Updating a land surface model with MODIS derived snow cover, Geophys. Res. Lett., 31, L20504, doi:10.1029/2004GL020873.

716 Schaake, J.C., Q. Duan, V. Koren, K.E. Mitchell, P.R. Houser, E.F. Wood, A. Robock, D.P. 717 Lettenmaier, D. Lohmann, B.A. Cosgrove, J. Sheffield, L. Luo, R.W. Higgins, R.T. 2004, J. Hydromet., 5(6), 1064-1075.

Sellers, P. J., Y. Mintz, Y. C. Sud, and A. Dalcher, 1986: A simple biosphere model (SiB) for Pinker, and J.D. Tarpley, 2004: An intercomparison of soil moisture fields in the North use within general circulation models. J. Atmos. Sci., 43, 505-531.

Sheffield, J., M. Pan, E.F. Wood, K.E. Mitchell, P.R. Houser, J.C. Schaake, A. Robock, D. Lohmann, B. Cosgrove, Q. Duan, L. Luo, R.W. Higgins, R.T. Pinker, J. Dan Tarpley, and B.H. Ramsay, 2003: Snow process modeling in the North American Land Data Assimilation System (NLDAS): 1. Evaluation of model-simulated snow cover extent. J. Geophys. Res., 108(D22), 8849, doi:10.1029/2002JD003274. 
Syed, T.H., J.S. Famiglietti, M. Rodell, J.L. Chen, and C.R. Wilson, 2008: Analysis of terrestrial water storage changes from GRACE and GLDAS. Water Resour. Res., 44, W02433, doi:10.1029/2006WR005779.

731

732

733

734

735

736

737

738

739

740

741

742

743

744

745

746

Troy, T.J., E.F. Wood, and J. Sheffield, 2008: An efficient calibration method for continentalscale land surface modeling. Water Resour. Res., 44, W09411, doi:10.1029/2007WR006513.

Wei, H., Y. Xia, K.E. Mitchell, and M.B. Ek, 2011: Improvement of the Noah Land Surface Model for Warm Season Processes: Evaluation of Water and Energy Flux Simulation. To be submitted to Geophys. Res. Letters.

Xia, Y., K. Mitchell, M. Ek, J. Sheffield, E.F. Wood, B. Cosgrove, L. Luo, C. Alonge, H. Wei, J. Meng, B. Livneh, D. Lettenmaier, V. Koren, Y. Duan, K. Mo, and Y. Fan, 2011a: Continental-Scale Water and Energy Flux Analysis and Validation for the NorthAmerican Land Data Assimilation System Project Phase 2 (NLDAS-2), Part 1: Comparison Analysis and Application of Model Products. To be submitted to J. Geophys. Res.

Xia, Y., K. Mitchell, M. Ek, J. Sheffield, B. Cosgrove, L. Luo, C. Alonge, H. Wei, J. Meng, B. Livneh, Y. Duan, and D. Lohmann, 2011b: Continental-Scale Water and Energy Flux Analysis and Validation for the North-American Land Data Assimilation System Project Phase 2 (NLDAS-2), Part 2: Validation of Model-Simulated Streamflow. To be submitted to J. Geophys. Res.

Xia, Y., M. Ek, H. Wei, and J. Meng, 2011c: Comparative Analysis of Relationships between NLDAS-2 Forcings and Model Outputs. Submitted to Hydrological Processes. 


\section{$751 \quad$ List of Tables}

753 Table 1: Parameters for perturbations to meteorological forcings and soil moisture prognostic

754 model variables in the data assimilation integrations.

755 Table 2: NLDAS domain-averaged root mean square and bias errors (all with 95\% confidence

756 intervals) in latent heat flux (Qle) and sensible heat flux (Qh) estimates from five LDAS

757 simulations with respect to two reference datasets : (1) the gridded FLUXNET data from Jung et

758 al., (2009) and (2) MOD16 data from Mu et al. (2011), which only provides Qle. Two of the

759 NLDAS simulations show differences due to Noah version, and two of the NLDAS simulations

760 include soil moisture data assimilation from the NASA and LPRM products, as discussed in the

761 text.

762

763 
765 Table 1: Parameters for perturbations to meteorological forcings and soil moisture 766 prognostic model variables in the data assimilation integrations.

\begin{tabular}{|c|c|c|c|c|c|c|}
\hline Variable & $\begin{array}{c}\text { Perturbation } \\
\text { Type }\end{array}$ & $\begin{array}{l}\text { Standard } \\
\text { Deviation }\end{array}$ & \multicolumn{4}{|c|}{$\begin{array}{c}\text { Cross Correlations with } \\
\text { perturbations in }\end{array}$} \\
\hline \multicolumn{7}{|c|}{ Meteorological Forcings } \\
\hline & & & $\begin{array}{l}\text { Downwarc } \\
\text { Shortwave }\end{array}$ & $\begin{array}{l}\text { Dowl } \\
\text { Long }\end{array}$ & $\begin{array}{l}\text { ward } \\
\text { wave }\end{array}$ & Precipitation \\
\hline $\begin{array}{l}\text { Downward } \\
\text { Shortwave }\end{array}$ & Multiplicative & $0.3[-]$ & 1.0 & & -0.5 & -0.8 \\
\hline $\begin{array}{l}\text { Downward } \\
\text { Longwave }\end{array}$ & Additive & $50 \mathrm{Wm}^{-2}$ & -0.5 & & 1.0 & 0.5 \\
\hline Precipitation & Multiplicative & $0.5[-]$ & -0.8 & & 0.5 & 1.0 \\
\hline \multicolumn{7}{|c|}{ Noah LSM soil moisture states } \\
\hline & & & Sm1 & Sm2 & Sm3 & Sm4 \\
\hline $\begin{array}{lr}\text { Total soil } \\
\text { moisture }\end{array}$ & Additive & ${ }_{3}^{0.6 \mathrm{E}-3 \mathrm{~m}^{3} \mathrm{~m}^{-}}$ & 1.0 & 0.6 & 0.4 & 0.2 \\
\hline $\begin{array}{lr}\text { Total soil } \\
\text { moisture } \\
\text { layer } 2(\mathrm{sm} 2)\end{array}$ & Additive & ${ }_{3}^{1.1 \mathrm{E}-4 \mathrm{~m}^{3} \mathrm{~m}^{-}}$ & 0.6 & 1.0 & 0.6 & 0.4 \\
\hline $\begin{array}{l}\text { Total soil } \\
\text { moisture } \\
\text { layer } 3(\mathrm{sm} 3)\end{array}$ & Additive & ${ }_{3}^{0.6 \mathrm{E}-5 \mathrm{~m}^{3} \mathrm{~m}^{-}}$ & 0.4 & 0.6 & 1.0 & 0.6 \\
\hline $\begin{array}{l}\text { Total soil } \\
\text { moisture } \\
\text { layer } 4(\mathrm{sm} 4)\end{array}$ & Additive & ${ }_{3}^{0.4 \mathrm{E}-5 \mathrm{~m}^{3} \mathrm{~m}^{-}}$ & 0.2 & 0.4 & 0.6 & 1.0 \\
\hline
\end{tabular}


770 Table 2: NLDAS domain-averaged root mean square and bias errors (all with 95\% 771 confidence intervals) in latent heat flux (Qle) and sensible heat flux (Qh) estimates from 772 five LDAS simulations with respect to two reference datasets : (1) the gridded FLUXNET 773 data from Jung et al., (2009) and (2) MOD16 data from Mu et al. (2011), which only 774 provides Qle. Two of the NLDAS simulations show differences due to Noah version, and 775 two of the NLDAS simulations include soil moisture data assimilation from the NASA and 776 LPRM products, as discussed in the text.

\begin{tabular}{|l|c|c|c|c|}
\hline & \multicolumn{2}{|c|}{ FLUXNET } & \multicolumn{2}{c|}{ MOD16 } \\
\hline Qle & $\begin{array}{l}\text { RMSE } \\
\left(\mathbf{W m}^{-2}\right)\end{array}$ & $\begin{array}{c}\text { Bias } \\
\left(\mathbf{W m}^{-2}\right)\end{array}$ & $\begin{array}{c}\text { RMSE } \\
\left.\mathbf{W m}^{-2}\right)\end{array}$ & $\begin{array}{c}\text { Bias } \\
\left.\mathbf{W m}^{-2}\right)\end{array}$ \\
\hline GLDAS & $24.7 \pm 0.3$ & $5.5 \pm 0.4$ & $28.0 \pm 0.2$ & $4.4 \pm 0.3$ \\
\hline NLDAS (Noah v2.7.1) & $19.3 \pm 0.3$ & $11.9 \pm 0.4$ & $21.5 \pm 0.2$ & $10.3 \pm 0.3$ \\
\hline NLDAS (Noah v3.2) & $27.6 \pm 0.3$ & $12.9 \pm 0.4$ & $22.7 \pm 0.2$ & $11.2 \pm 0.3$ \\
\hline NLDAS (Noah v3.2)+NASA DA & $29.4 \pm 0.3$ & $15.9 \pm 0.4$ & $24.5 \pm 0.2$ & $14.2 \pm 0.3$ \\
\hline NLDAS (Noah v3.2)+LPRM DA & $25.6 \pm 0.3$ & $10.9 \pm 0.3$ & $21.9 \pm 0.2$ & $9.2 \pm 0.3$ \\
\hline Qh & & & & \\
\hline GLDAS & $23.4 \pm 0.2$ & $-5.6 \pm 0.4$ & N/A & N/A \\
\hline NLDAS (Noah v2.7.1) & $21.1 \pm 0.3$ & $-7.0 \pm 0.4$ & N/A & N/A \\
\hline NLDAS (Noah v3.2) & $32.5 \pm 0.3$ & $-9.2 \pm 0.4$ & N/A & N/A \\
\hline NLDAS (Noah v3.2)+NASA DA & $34.5 \pm 0.3$ & $-12.2 \pm 0.4$ & N/A & N/A \\
\hline NLDAS (Noah v3.2)+LPRM DA & $30.4 \pm 0.3$ & $-7.3 \pm 0.4$ & & \\
\hline
\end{tabular}


Figure 1: Schematic illustrating the data flows in an uncoupled Land Data Assimilation System. As shown, input parameter and meteorological data or "forcings" can obtained from various sources. If data assimilation is employed, the observations of land surface states can be used to update model states using various data assimilation approaches, such as Direct Insertion (DI) or

787 Figure 2: Comparison of the average seasonal cycles of RMSE and Bias for latent heat flux (Qle) estimates from the three LDAS simulations: GLDAS Noah, NLDAS-like simulations with Noah 2.7.1 (NLDAS-N271) and Noah 3.2 (NLDAS-N32) compared against the gridded FLUXNET data (left column) and MOD16 data (right column). All units are in $\mathrm{Wm}^{-2}$

791 Figure 3:Intercomparison of seasonally-averaged Qle for the period Jan 2002-Dec 2008 over the

792 NLDAS domain from five sources: gridded FLUXNET (Jung et al., 2010); MOD16 data (Mu et 793 al. 2011); GLDAS Noah (Rodell et al., 2004); NLDAS-like simulations with Noah 2.7.1 and 794 Noah3.2 produced using LIS (Kumar et al., 2006). All units are in $\mathrm{Wm}^{-2}$. 43

795 Figure 4: Comparison of the seasonal cycles of RMSE and Bias in Qle estimates from NLDAS796 equivalent simulations for the period Jan 2002- Dec 2008 against the gridded FLUXNET data 797 (left column) and MOD16 data (right column). The comparisons present the impact of the 798 assimilation of surface soil moisture retrievals on latent heat flux estimates. OL represents the 799 “open loop” model simulation without data assimilation, which is equivalent to the NLDAS-N32 800 curves in Figure 2. NASA-DA and LPRM-DA represents simulations that assimilate the NASA 801 and LPRM retrievals of AMSR-E soil moisture, respectively. All units are in $\mathrm{Wm}^{-2}$. 44

802 Figure 5: Comparison of the latent heat flux improvement metric (RMSE (DA) - RMSE (OL)) 803 from the data assimilation integrations using the NASA AMSR-E soil moisture retrievals 804 (NASA-DA). The two columns represent the reference datasets used in the RMSE computations: 805 FLUXNET (left column) and MOD16 (right column). The red and blue shades indicate 806 improvements and degradations as a result of data assimilation, respectively. All units are in $807 \mathrm{Wm}^{-2}$.

808 Figure 6: Same as Figure 5, but from data assimilation integrations using LPRM AMSR-E soil 809 moisture retrievals (LPRM-DA). 
810 Figure 7: Comparison of the mean soil moisture difference maps (soil moisture (DA) - soil

811 moisture (OL)) from soil moisture data assimilation integrations. The left and right panels

812 represent the NASA-DA and LPRM-DA, respectively. All units are in $\mathrm{m}^{3} \mathrm{~m}^{-3}$.......................... 48

813

814 


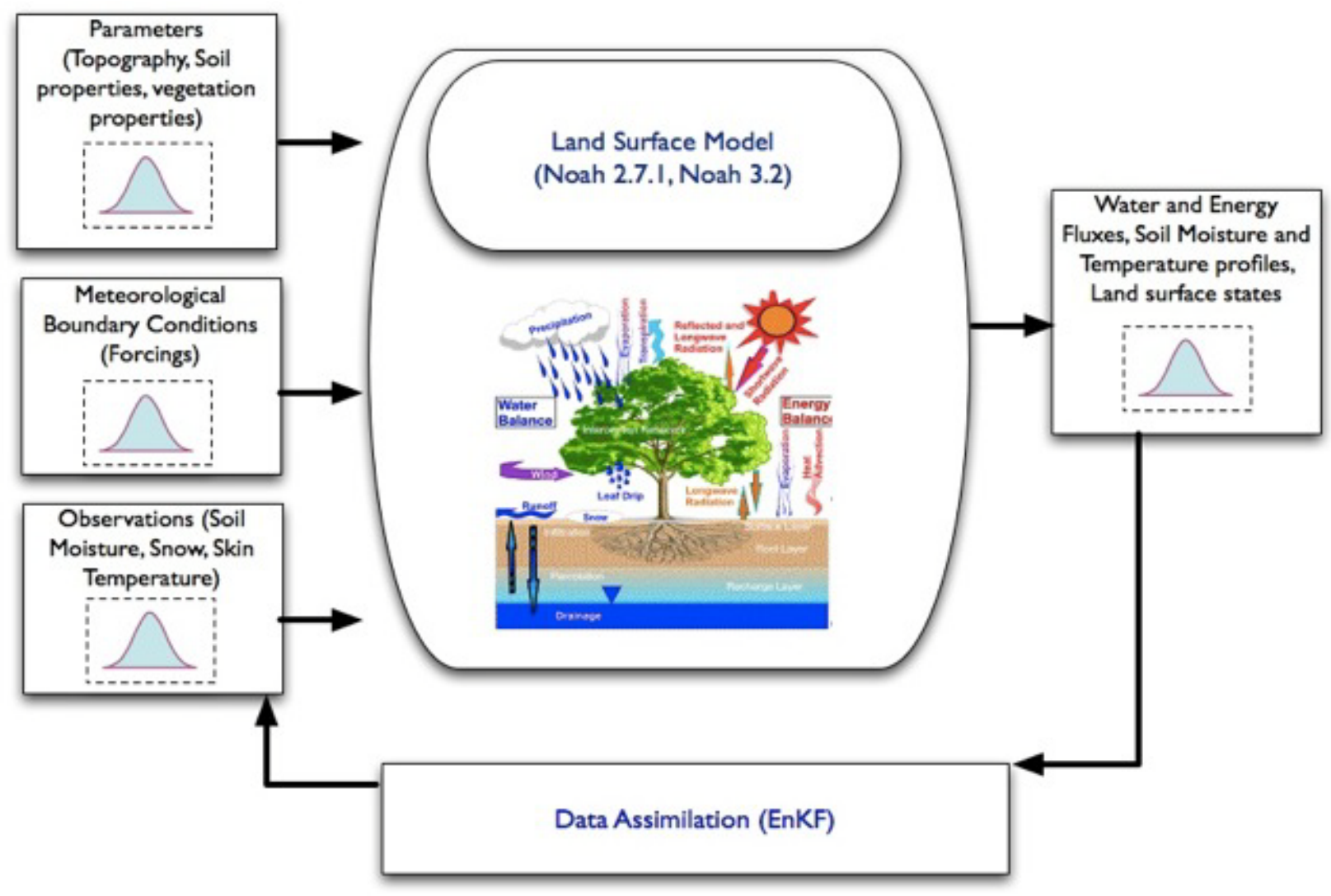

816 Figure 1: Schematic illustrating the data flows in an uncoupled Land Data Assimilation

817 System. As shown, input parameter and meteorological data or “forcings" can obtained

818 from various sources. If data assimilation is employed, the observations of land surface

819 states can be used to update model states using various data assimilation approaches, such 820 as Direct Insertion (DI) or Ensemble Kalman Filter (EnKF). 
FLUXNET

RMSE

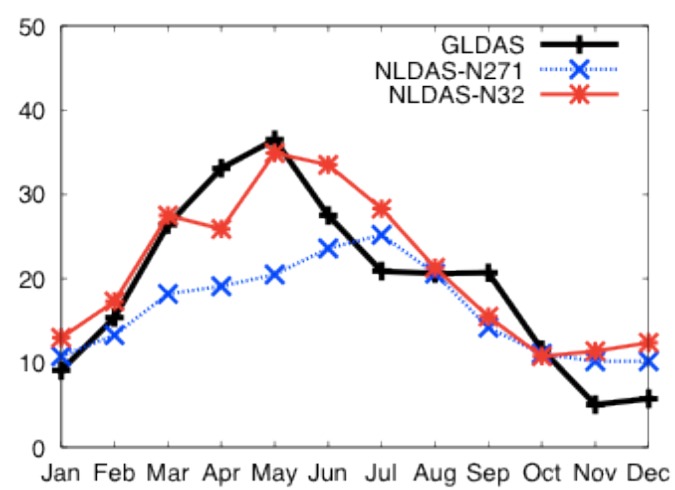

Bias

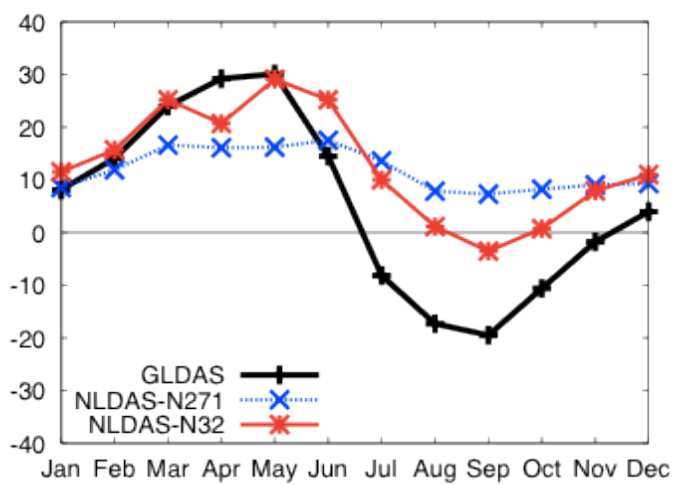

MOD16
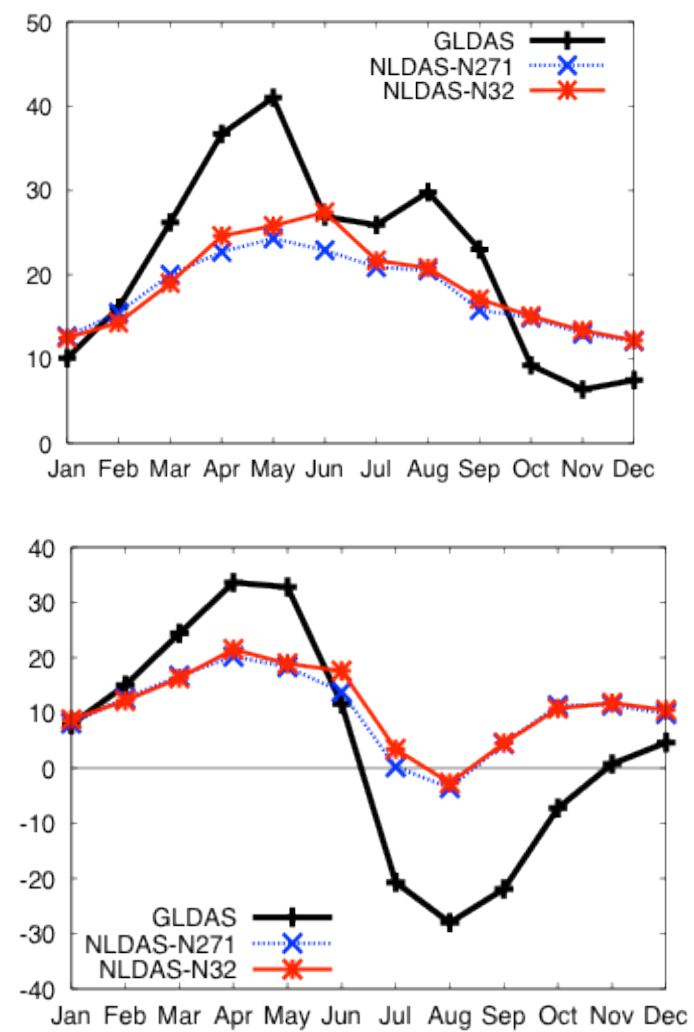

824 Figure 2: Comparison of the average seasonal cycles of RMSE and Bias for latent heat flux 825 (Qle) estimates from the three LDAS simulations: GLDAS Noah, NLDAS-like simulations 826 with Noah 2.7.1 (NLDAS-N271) and Noah 3.2 (NLDAS-N32) compared against the gridded 827 FLUXNET data (left column) and MOD16 data (right column). All units are in Wm ${ }^{-2}$. 
DJF

FLUXNET
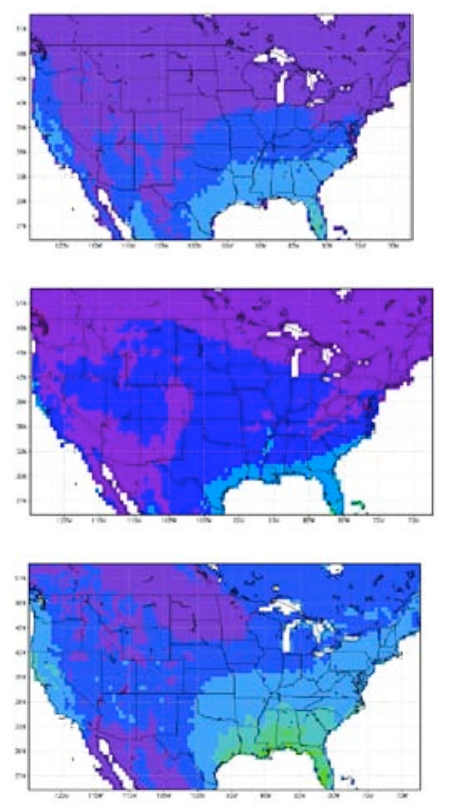

GLDAS

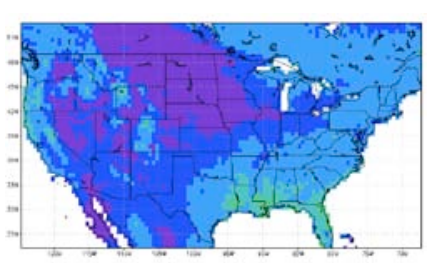

NLDAS

(Noah 2.7.1)

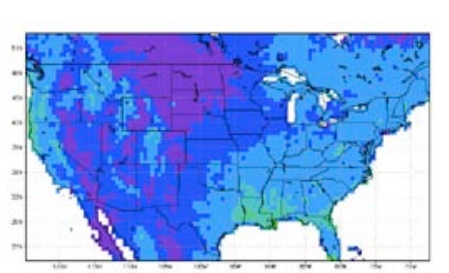

NLDAS

(Noah 3.2)
MAM
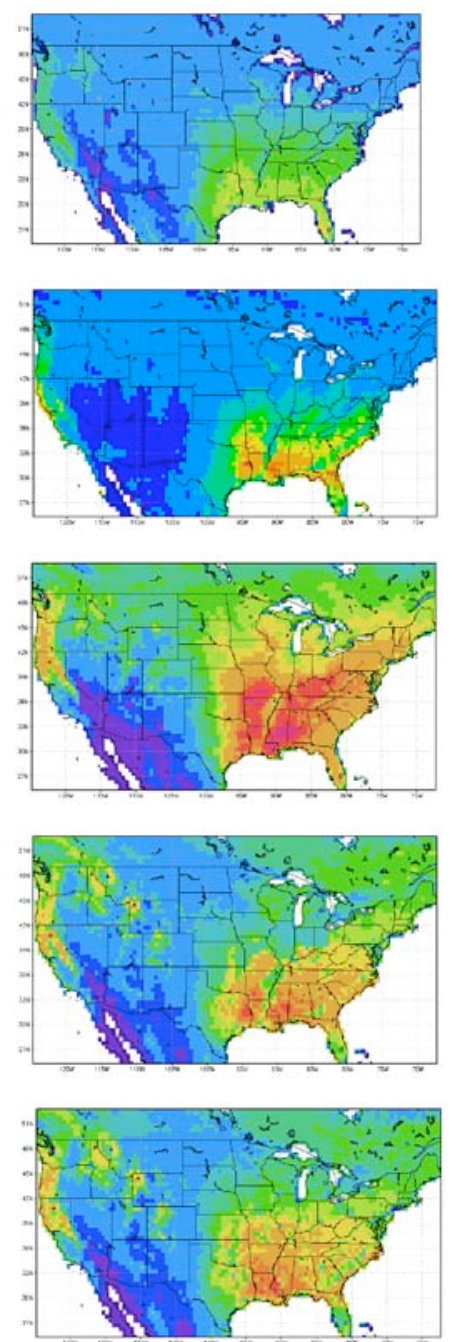

JJA
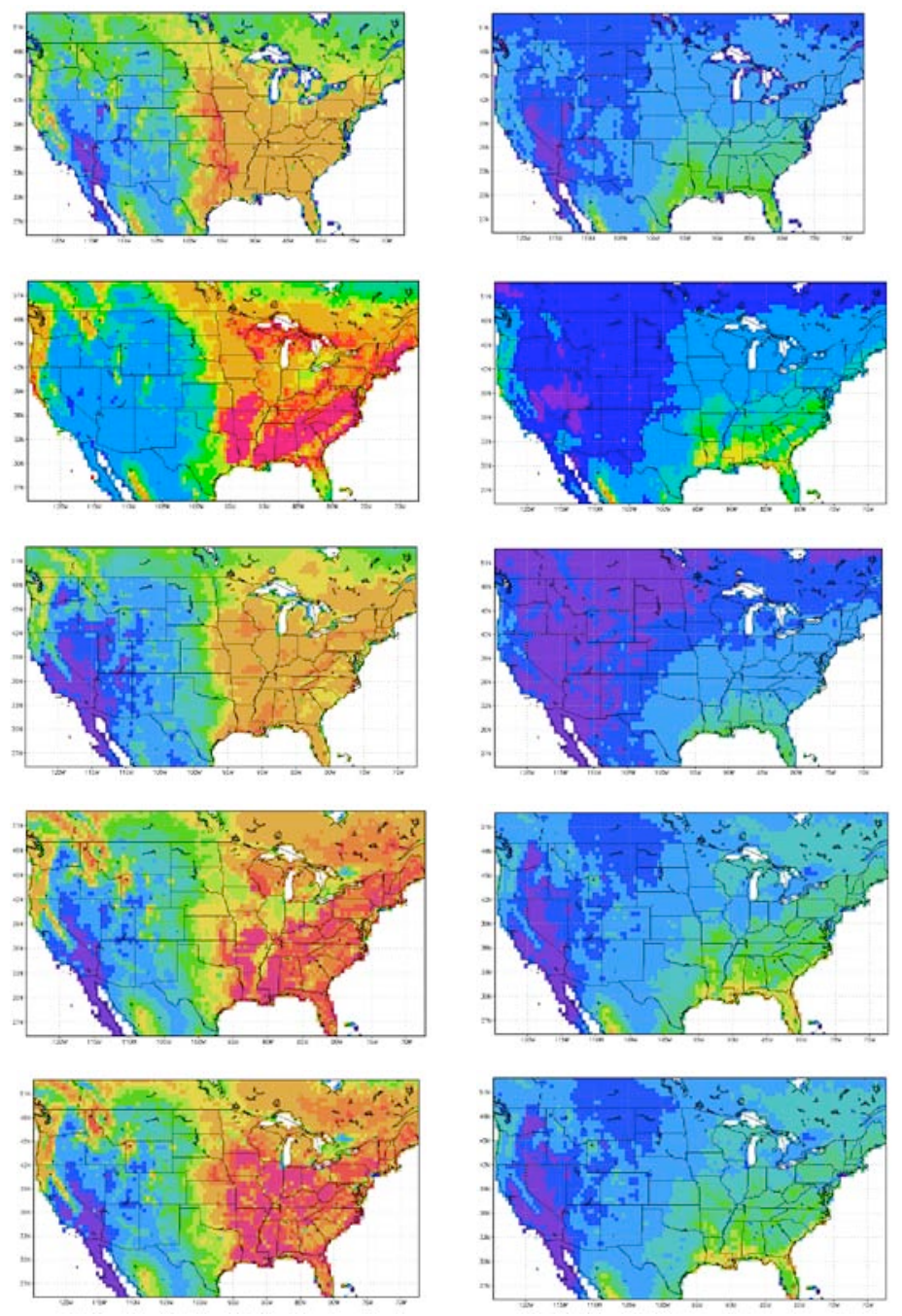

SON
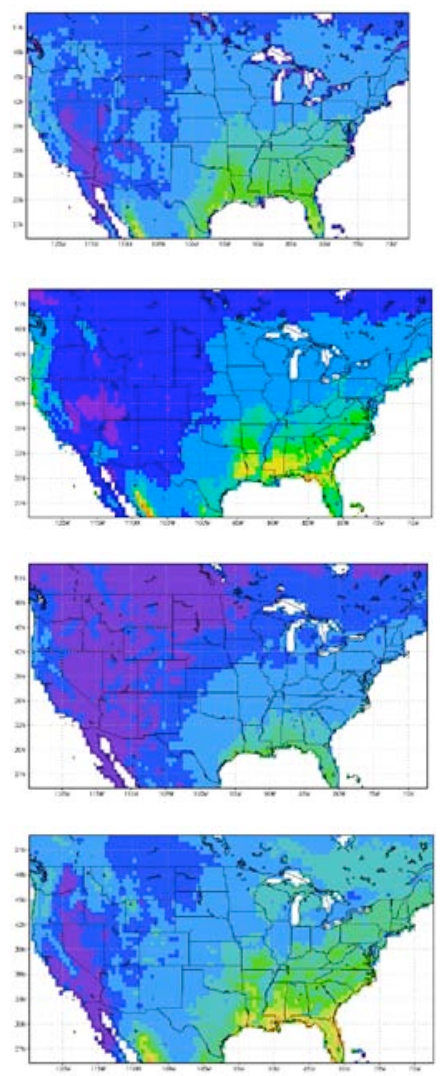

Figure 3:Intercomparison of seasonally-averaged Qle for the period Jan 2002-Dec 2008 over the NLDAS domain from five sources: gridded FLUXNET (Jung et al., 2010); MOD16 data (Mu et al. 2011); GLDAS Noah (Rodell et al., 2004); NLDAS-like simulations with Noah 2.7.1 and Noah3.2 produced using LIS (Kumar et al., 2006). All units are in $\mathrm{Wm}^{-2}$. 
FLUXNET

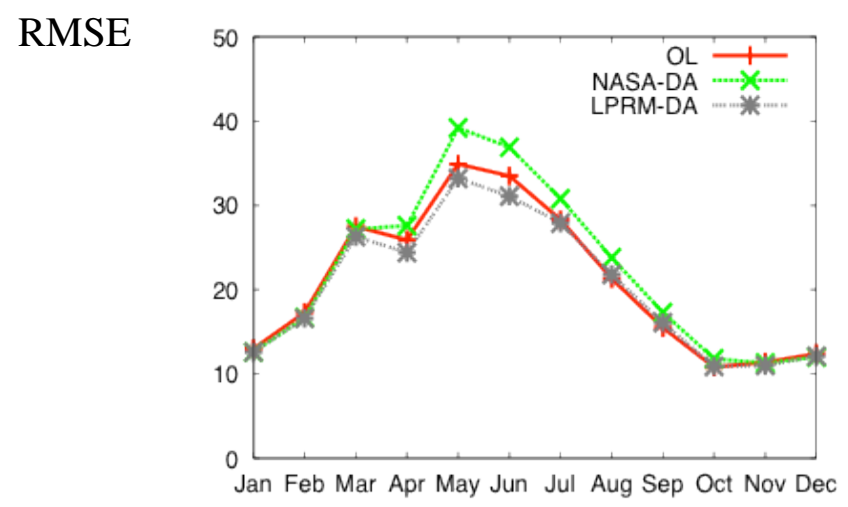

Bias

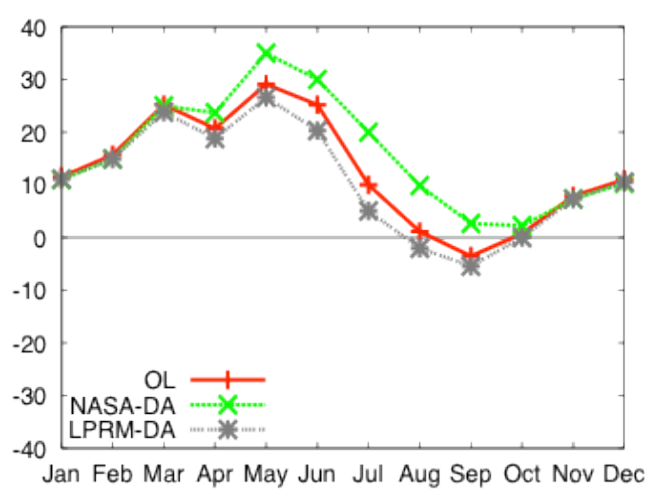

MOD16
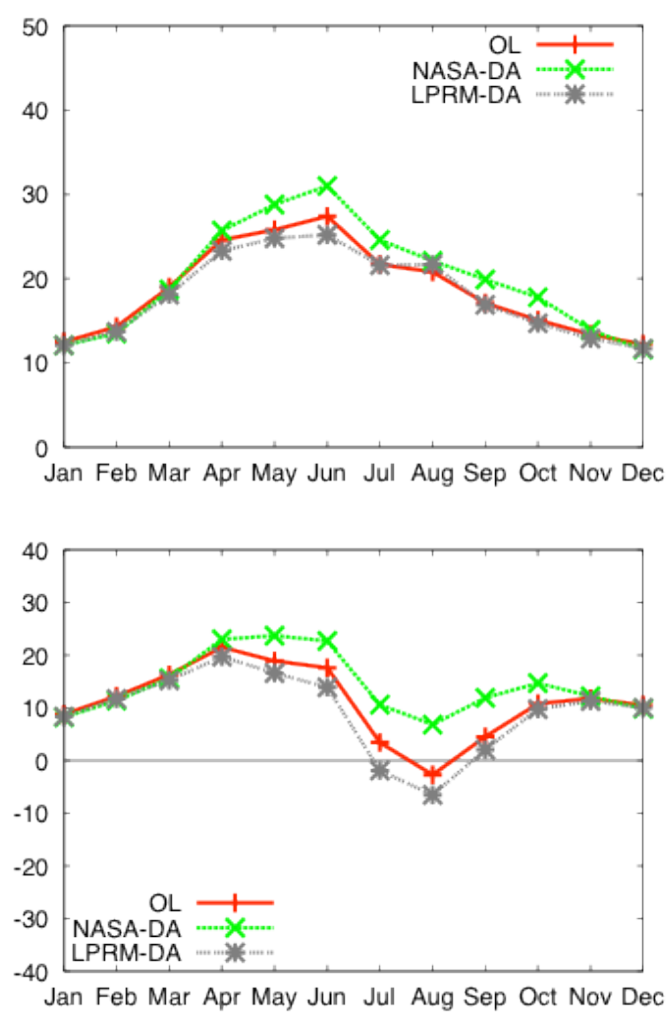

836 Figure 4: Comparison of the seasonal cycles of RMSE and Bias in Qle estimates from

837 NLDAS-equivalent simulations for the period Jan 2002- Dec 2008 against the gridded 838 FLUXNET data (left column) and MOD16 data (right column). The comparisons present 839 the impact of the assimilation of surface soil moisture retrievals on latent heat flux 840 estimates. OL represents the “open loop” model simulation without data assimilation, 841 which is equivalent to the NLDAS-N32 curves in Figure 2. NASA-DA and LPRM-DA 842 represents simulations that assimilate the NASA and LPRM retrievals of AMSR-E soil moisture, respectively. All units are in $\mathrm{Wm}^{-2}$. 
FLUXNET

DJF

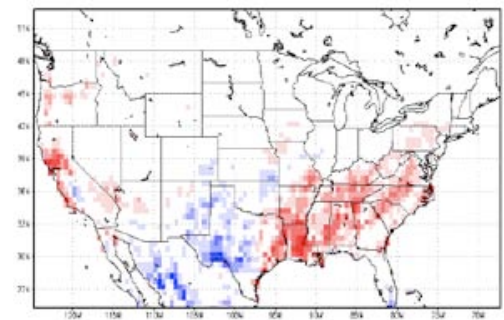

MAM

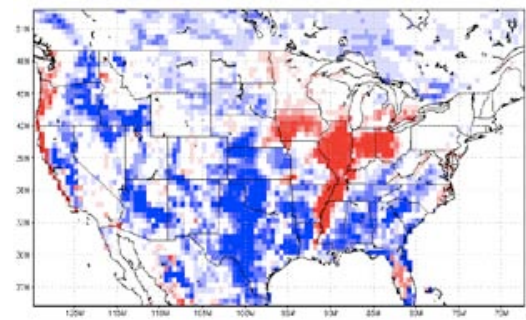

JJA

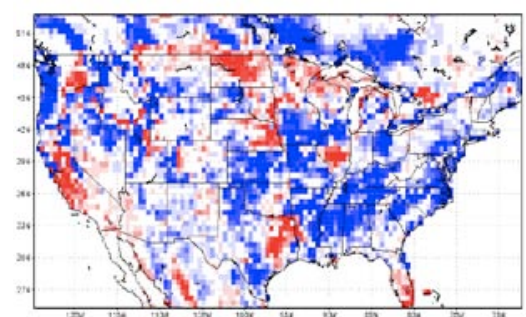

SON

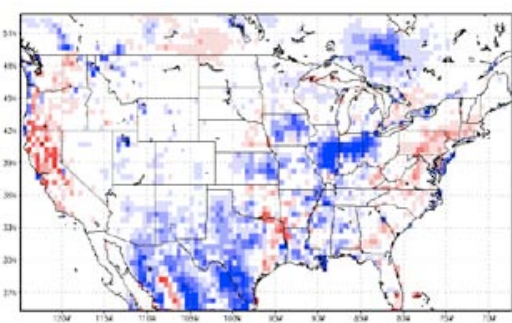

MOD16
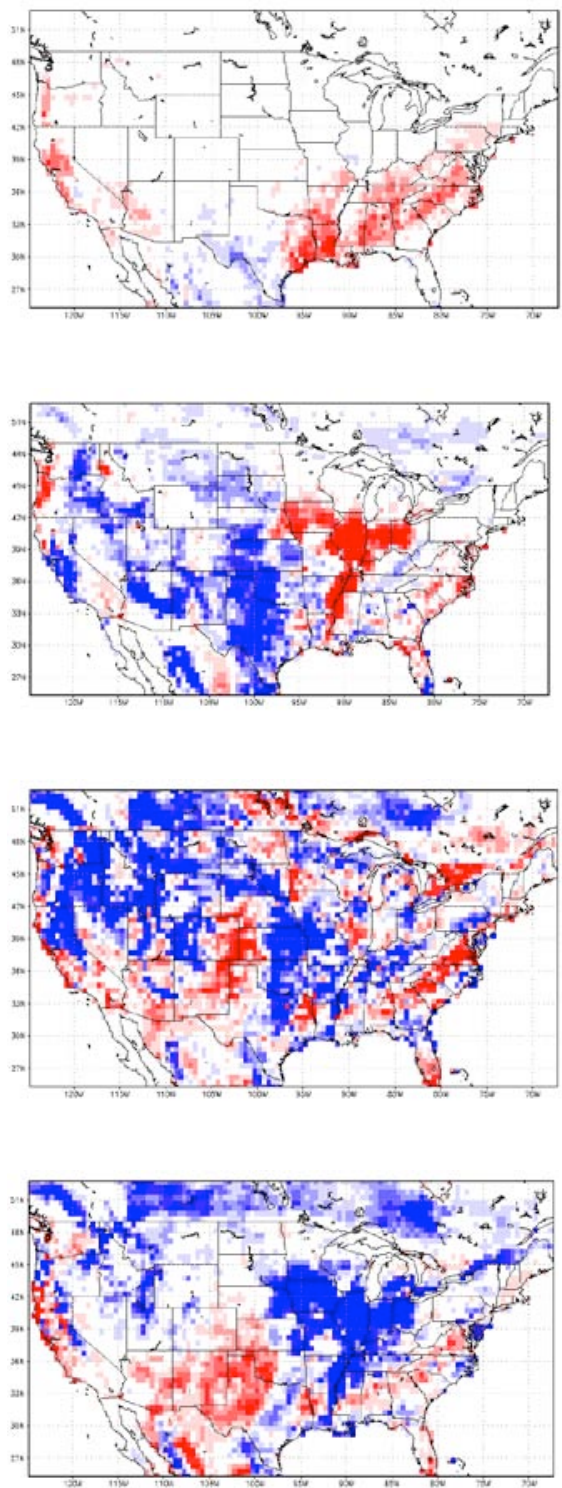

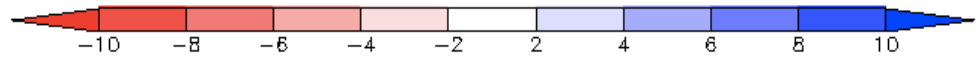

846 Figure 5: Comparison of the latent heat flux improvement metric (RMSE (DA) - RMSE 847 (OL)) from the data assimilation integrations using the NASA AMSR-E soil moisture 848 retrievals (NASA-DA). The two columns represent the reference datasets used in the 849 RMSE computations: FLUXNET (left column) and MOD16 (right column). The red and 
850 blue shades indicate improvements and degradations as a result of data assimilation, 851 respectively. All units are in $\mathrm{Wm}^{-2}$.

852

853 
854

FLUXNET

DJF

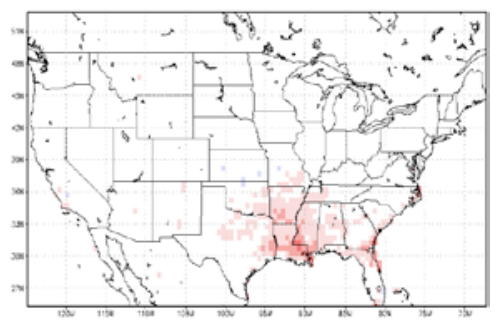

MAM

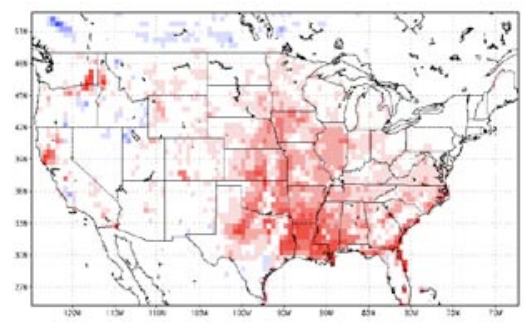

JJA

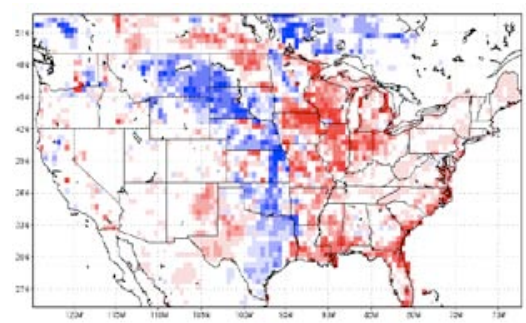

SON

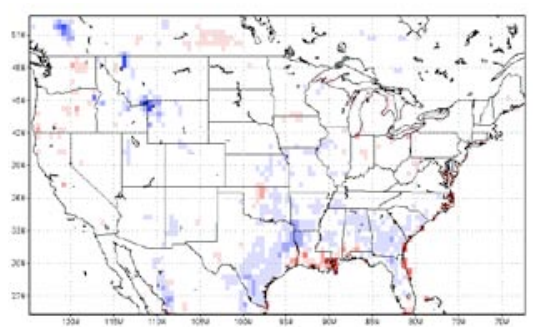

MOD16
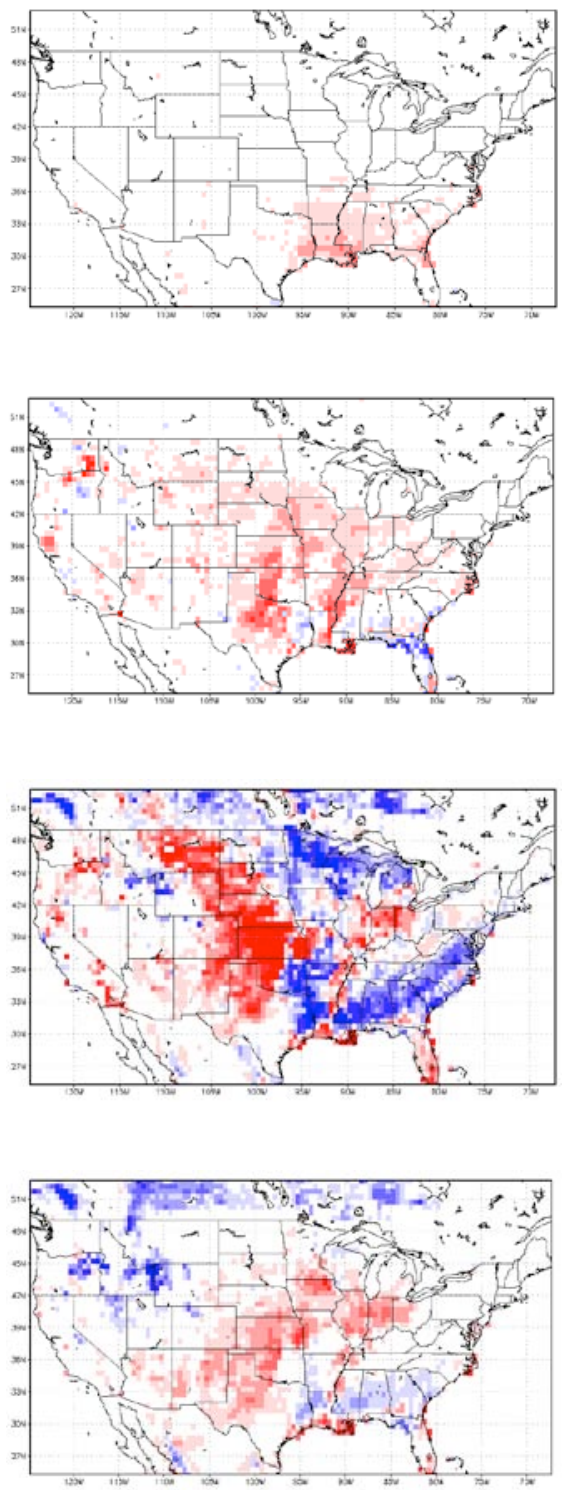

855 Figure 6: Same as Figure 5, but from data assimilation integrations using LPRM AMSR-E 856 soil moisture retrievals (LPRM-DA).

857 
NASA-DA

DJF

MAM

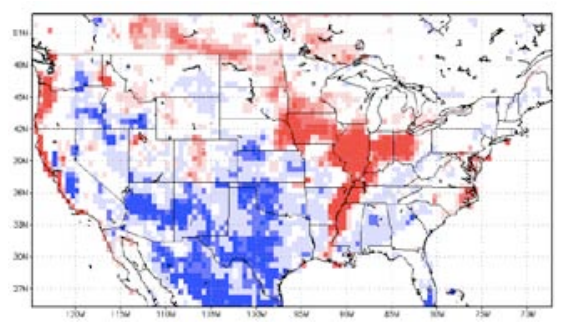

JJA
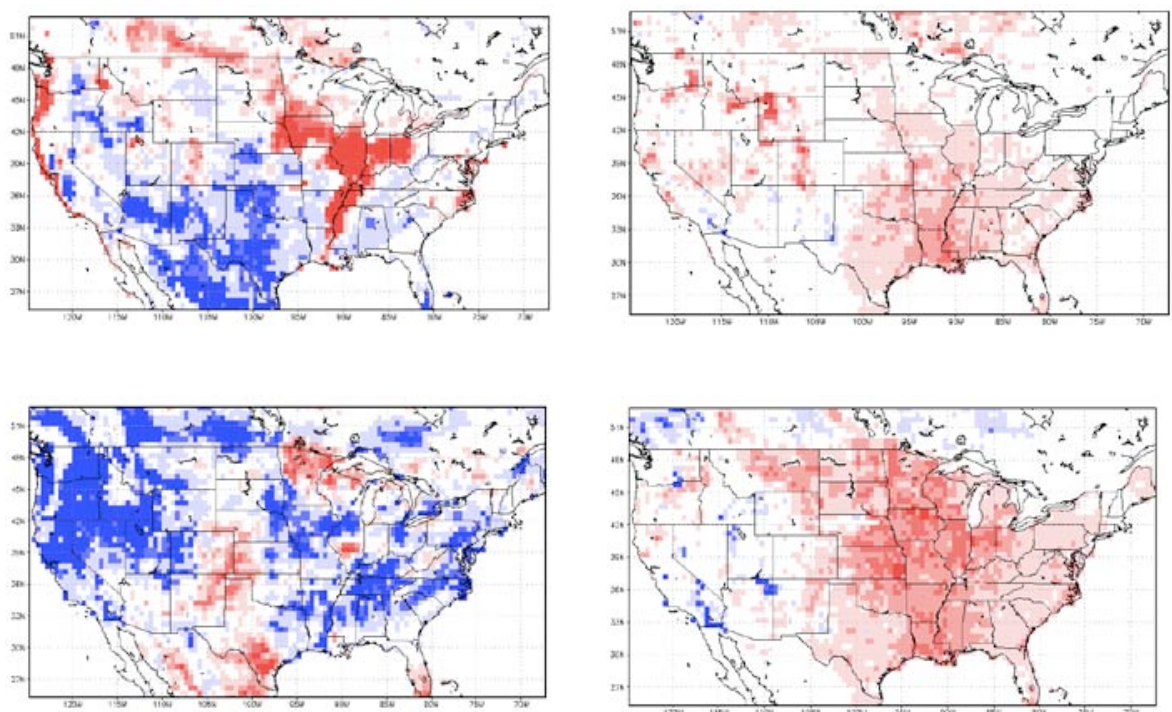

SON
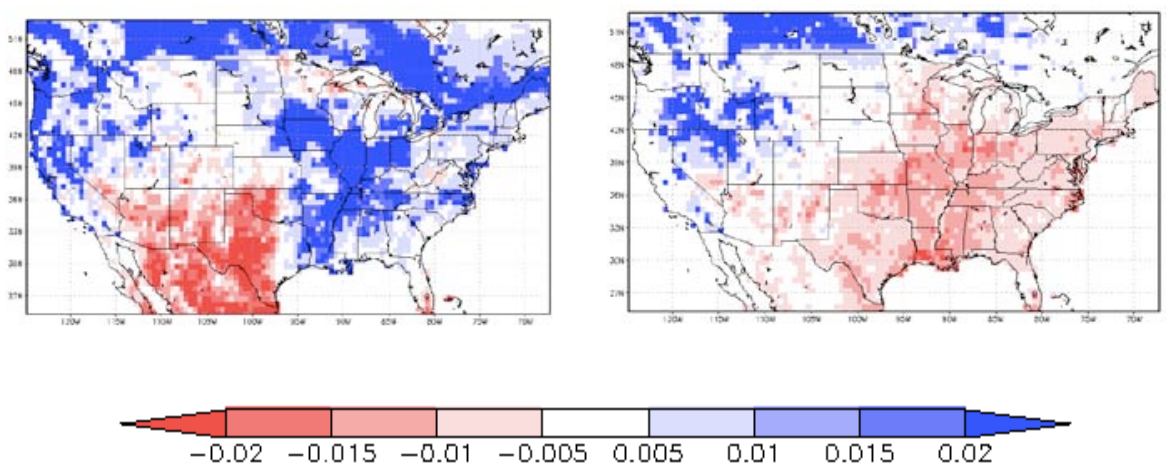

860 Figure 7: Comparison of the mean soil moisture difference maps (soil moisture (DA) - soil 861 moisture (OL)) from soil moisture data assimilation integrations. The left and right panels 862 